NASA/TM-2008-215546

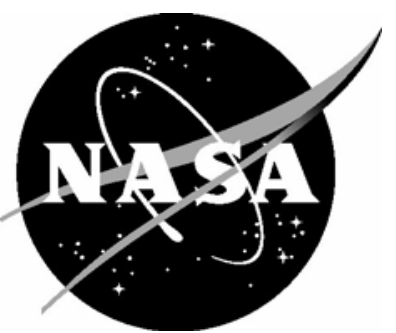

\title{
A Performance Assessment of a Tactical Airborne Separation Assistance System Using Realistic, Complex Traffic Flows
}

Jeremy C. Smith and Kurt W. Neitzke

Langley Research Center, Hampton, Virginia

Frank J. L. Bussink

National Institute of Aerospace, Hampton, Virginia 
Since its founding, NASA has been dedicated to the advancement of aeronautics and space science. The NASA Scientific and Technical Information (STI) Program Office plays a key part in helping NASA maintain this important role.

The NASA STI Program Office is operated by Langley Research Center, the lead center for NASA's scientific and technical information. The NASA STI Program Office provides access to the NASA STI Database, the largest collection of aeronautical and space science STI in the world. The Program Office is also NASA's institutional mechanism for disseminating the results of its research and development activities. These results are published by NASA in the NASA STI Report Series, which includes the following report types:

- TECHNICAL PUBLICATION. Reports of completed research or a major significant phase of research that present the results of NASA programs and include extensive data or theoretical analysis. Includes compilations of significant scientific and technical data and information deemed to be of continuing reference value. NASA counterpart of peerreviewed formal professional papers, but having less stringent limitations on manuscript length and extent of graphic presentations.

- TECHNICAL MEMORANDUM. Scientific and technical findings that are preliminary or of specialized interest, e.g., quick release reports, working papers, and bibliographies that contain minimal annotation. Does not contain extensive analysis.

- CONTRACTOR REPORT. Scientific and technical findings by NASA-sponsored contractors and grantees.
- CONFERENCE PUBLICATION. Collected papers from scientific and technical conferences, symposia, seminars, or other meetings sponsored or co-sponsored by NASA.

- SPECIAL PUBLICATION. Scientific, technical, or historical information from NASA programs, projects, and missions, often concerned with subjects having substantial public interest.

- TECHNICAL TRANSLATION. Englishlanguage translations of foreign scientific and technical material pertinent to NASA's mission.

Specialized services that complement the STI Program Office's diverse offerings include creating custom thesauri, building customized databases, organizing and publishing research results ... even providing videos.

For more information about the NASA STI Program Office, see the following:

- Access the NASA STI Program Home Page at http://www.sti.nasa.gov

- E-mail your question via the Internet to help@sti.nasa.gov

- Fax your question to the NASA STI Help Desk at (301) 621-0134

- Phone the NASA STI Help Desk at (301) 621-0390

- Write to: NASA STI Help Desk NASA Center for AeroSpace Information 7115 Standard Drive Hanover, MD 21076-1320 
NASA/TM-2008-215546

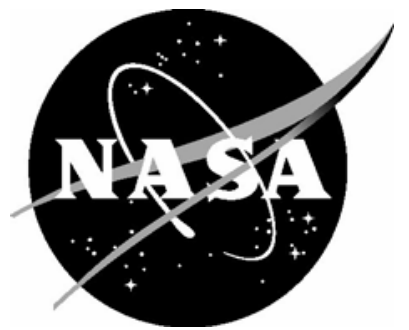

\section{A Performance Assessment of a Tactical Airborne Separation Assistance System Using Realistic, Complex Traffic Flows}

Jeremy C. Smith and Kurt W. Neitzke

Langley Research Center, Hampton, Virginia

Frank J. L. Bussink

National Institute of Aerospace, Hampton, Virginia

National Aeronautics and

Space Administration 


\section{Acknowledgments}

The authors gratefully acknowledge the assistance of Jason A. Solimani and Gregory A. Wrenn, ATK, Langley Research Center, Hampton, Virginia, and Cesar Munoz, National Institute of Aerospace, Hampton, Virginia, during this study.

Available from:

NASA Center for AeroSpace Information (CASI)

7115 Standard Drive

Hanover, MD 21076-1320

(301) 621-0390
National Technical Information Service (NTIS) 5285 Port Royal Road Springfield, VA 22161-2171

(703) 605-6000 


\section{Background}

The context for this work derives from NASA's Aeronautics Research Mission Directorate (ARMD), working as a member agency of the Joint Planning and Development Office (JPDO), to provide foundational research supporting the development of "The Next Generation Air Transportation System (NextGen)”. NextGen refers to “a wide-ranging initiative to transform the air traffic control system"1 according to the JPDO, which includes among its principal member agencies, both NASA and the FAA. The JPDO is charged to “. . . . create, and carry out an integrated plan for NextGen, spearhead planning, and coordinate research, demonstrations and development in conjunction with relevant programs of other departments and agencies, and with the private sector."2 Accordingly, safely increasing the capacity of the National Airspace System (NAS) to accommodate up to three times current levels of flight demand are a primary objective of the JPDO in the development of NextGen.

Prior to the JPDO's establishment in 2003, NASA-Aeronautics began developing a farterm, transformational concept called Distributed Air/Ground-Traffic Management (DAGTM), which pursued many of the same objectives. Under DAG-TM, NAS users would share information, collaborate on decision-making and distribute decision authority to the most appropriate decision maker, with the goal of improving system capacity as well as increasing flexibility and efficiency.

Following the completion of DAG-TM in September of 2004, NASA's Aeronautics Research Mission Directorate (ARMD) comprehensively re-planned its research investments. This resulted in the establishment of two projects within the new Airspace Systems Program (ASP), the NextGen Airspace and NextGen Airportal Projects. Both projects support the JPDO in the course of developing NextGen.

This study is Task 49 of the System-Level Design Analysis and Simulation Tools (SLDAST) Research Focus Area (RFA) of the NASA Airspace Project.

\footnotetext{
${ }^{1}$ From JPDO website: http://www.jpdo.gov/faq.asp\#31 under “What is NextGen?”

${ }^{2}$ From JPDO website: http://www.jpdo.gov/faq.asp\#3 under "What does the Joint Planning and Development Office do?”
} 


\section{TABLE OF CONTENTS}

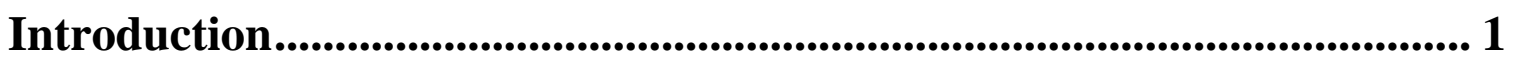

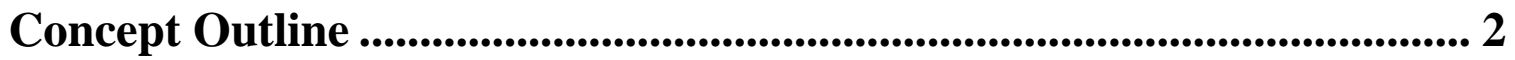

Research Objectives............................................................................................... 4

Simulation Setup ............................................................................................................ 5

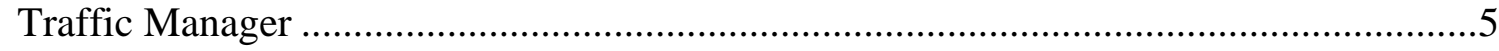

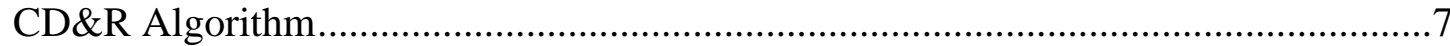

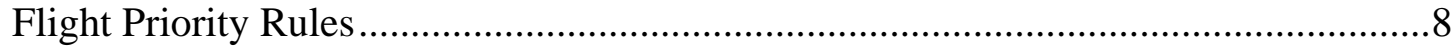

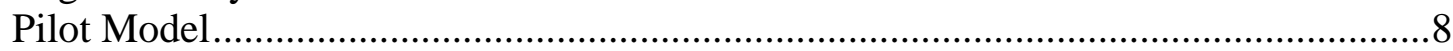

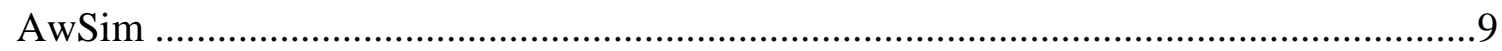

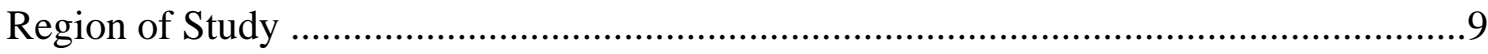

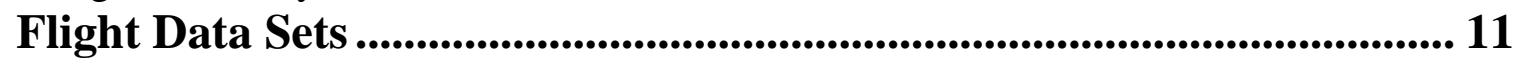

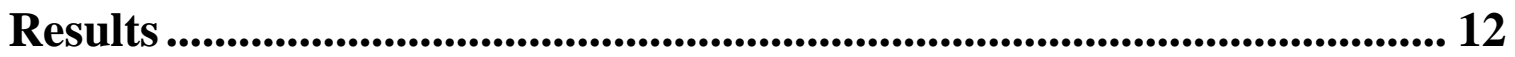

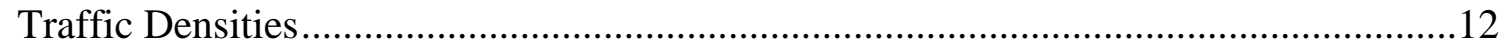

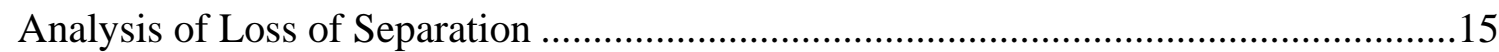

Discussion of Causes of Loss of Separation ...........................................................15

Detailed Analysis of Three Selected Loss of Separation..............................................21

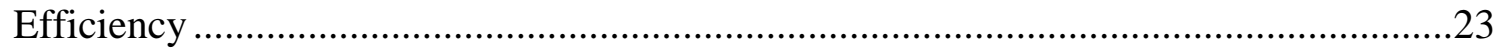

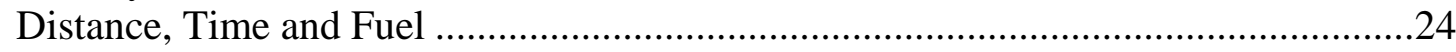

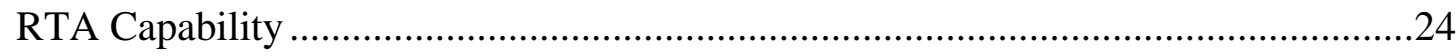

Discussion of Results................................................................................. 26

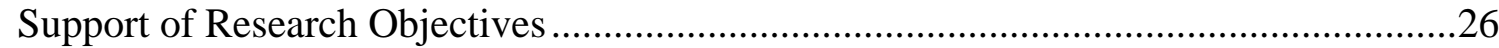

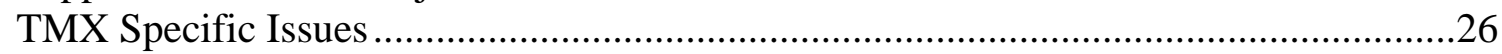

KB3D Specific Issues ............................................................................................27

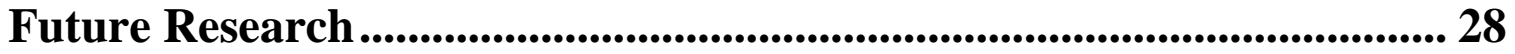

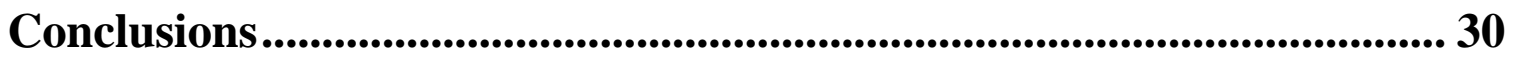

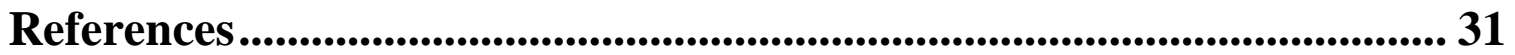




\section{FIGURES}

Figure 1. TMX user interface showing AFR aircraft (green) and IFR aircraft (blue)..........6

Figure 2. TMX conflict prevention bands for heading, speed and vertical rate....................6

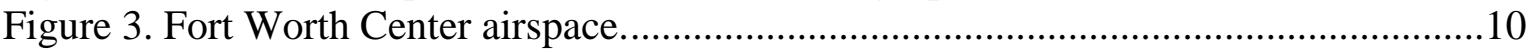

Figure 4. Experiment airspace........................................................................... 10

Figure 5. Number of aircraft in busiest ZFW sector (ZFW4201 High)............................13

Figure 6. Example of pilot model/ conflict prevention system failure ..............................21

Figure 7. Example of poor recovery maneuver............................................................21

Figure 8. Example of four aircraft encounter..............................................................22

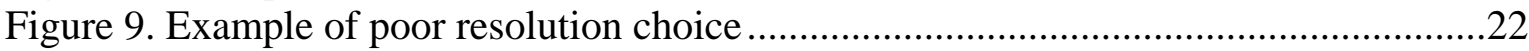

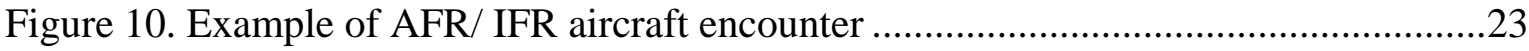

Figure 11. Example of IFR maneuver into short-term conflict....................................23

Figure 12. Difference in actual and required time at arrival fix......................................25

\section{TABLES}

Table 1. Flight data sets used in simulation.............................................................11

Table 2. Number of aircraft in the simulation..........................................................12

Table 3. Conflicts and losses of separation within experiment volume............................14

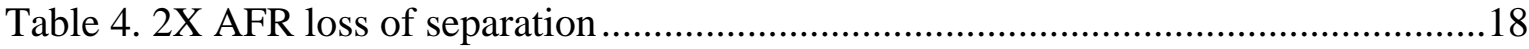

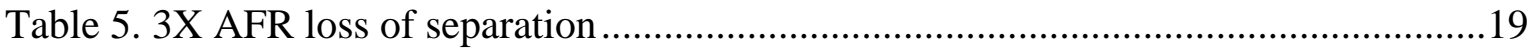

Table 6. 1X AFR plus 1X IFR mixed equipage loss of separation....................................20

Table 7. Mean increase in flight distance, time and fuel used. ......................................24

Table 8. Percentage of flights meeting RTA................................................................25 


\section{Introduction}

This report presents the results from a study that investigates the performance of a tactical Airborne Separation Assistance System (ASAS) in en route airspace, under varying demand levels, with realistic traffic flows. The ASAS concept studied here allows flight crews of equipped aircraft to perform separation from other air traffic autonomously.

This study addresses the tactical aspects of an ASAS using aircraft state data (i.e. position and velocity) to detect and resolve projected conflicts. In addition, use of a conflict prevention system helps ASAS-equipped aircraft avoid maneuvers that may cause new conflicts. ASAS-capable aircraft are equipped with satellite-based navigation and Automatic Dependant Surveillance Broadcast (ADS-B) for transmission and receipt of aircraft state data.

In addition to tactical conflict detection and resolution (CD\&R), a complete, integrated ASAS is likely to incorporate a strategic CD\&R component with a longer look-ahead time, using trajectory intent information. A system-wide traffic flow management (TFM) component, located at the FAA command center helps aircraft to avoid regions of excessive traffic density and complexity. A Traffic Alert and Collision Avoidance System (TCAS), as used today is the system of last resort. This integrated approach avoids sole reliance on the use of the tactical CD\&R studied here, but the tactical component remains a critical element of the complete ASAS.

The focus of this study is to determine to what extent the proposed tactical component of ASAS alone can maintain aircraft separation at demand levels up to three times that of current traffic. The study also investigates the effect of mixing ASAS-equipped aircraft with unequipped aircraft (i.e. current day) that do not have the capability to self-separate. Position and velocity data for unequipped aircraft need to be available to ASAS-equipped aircraft. Most likely, for this future concept, state data would be available from instrument flight rules (IFR) aircraft, equipped with at least ADS-B transmission capability.

The objective is to reduce the number of losses of separation to a minimum and investigate the limits of tactical-only CD\&R. Thus, the objective is not, expressly, to achieve zero losses of separation with tactical ASAS because this is one component of an integrated ASAS. 


\section{Concept Outline}

The ASAS concept analyzed here has the potential to allow the flight crew of equipped aircraft to assume responsibility for separation during the en route phase of flight. This can potentially increase airspace capacity that today is primarily limited by the workload constraints of air traffic controllers.

The concept may also increase the flow of traffic through an airport by enabling aircraft to meet a required time of arrival (RTA) at the arrival fix. Accurately meeting an RTA evens out traffic flow and reduces spacing uncertainty. The capability to meet an RTA is a key element of the Next Generation Air Transportation System (NextGen) trajectory-based operations (TBO) concept, as defined in the Joint Planning and Development Office (JPDO) concept of operations (CONOPS) [1].

In addition to capacity gains, ASAS may also increase the efficiency of flight by allowing more direct routing compared with the routes in use today. Airlines and flight crews gain flexibility to modify routes during flight while remaining within NAS constraints.

The ASAS concept directly addresses transition path issues between today's IFR operations to a future state where IFR traffic safely inter-operates with self-separating ASAS operations.

The concept investigated in this study makes use of an automated, flight-deck based system for CD\&R, combined with a conflict prevention system to prevent aircraft maneuvers from creating new conflicts. The KB3D [2] algorithm was used for tactical CD\&R, combined with a conflict prevention system known as Predictive-ASAS (P-ASAS) [3]. This combination is referred to as Tactical ASAS in this report.

Upon detection of a potential conflict, a flight-deck display indicates one or more possible resolution maneuvers to the pilot. The P-ASAS provides information that the pilot can use to avoid additional, secondary conflicts (e.g. within the ensuing 3 minutes). Therefore, the pilot makes the final selection of maneuver.

ASAS aircraft are equipped with a Flight Management System (FMS) with the capability to meet an RTA. This FMS enables the aircraft to meet flow-management constraints. These constraints may include required time and position of airspace-region crossing points and required arrival time at an airport arrival fix.

Thus, using ASAS, in properly equipped aircraft, trained crews can assume responsibility for traffic separation. Such crews would be free to modify their flight path in real time, without approval from an air traffic controller as long as the trajectory meets all flowmanagement constraints.

The concept necessitates that self-separating flights operate under a new set of flight rules called autonomous flight rules (AFR). The AFR flights are required to maintain separation from all other aircraft. Using a set of priority rules (described in the Simulation Setup section), one aircraft in the pair in conflict is required to maneuver first, with the other aircraft maneuvering if the situation becomes urgent. 
In a mixed equipage environment, AFR aircraft are also required to maintain separation from aircraft operating under IFR and must give priority to such aircraft. Air traffic controllers would issue flow-management constraints to all aircraft and continue to provide separation among IFR aircraft, accommodating those operators who choose not to equip for AFR. In all likelihood, controllers would need to be aware of the presence of AFR aircraft and avoid maneuvering IFR aircraft into short-term conflicts with AFR. However, controller actions in a mixed equipage environment are not within the scope of this study. 


\section{Research Objectives}

The main objectives of this research are to:

1. Investigate the extent that Tactical ASAS alone can accommodate current demand levels, while efficiently resolving conflicts.

2. Investigate the performance of Tactical ASAS alone as demand levels increase to twice and three times current demand levels.

3. Investigate the integration of ASAS equipped aircraft with non-equipped aircraft in non-segregated airspace.

4. Investigate the extent that existing modeling and simulation tools can address the research issues, identifying gaps or issues that require further investment in tools and algorithm development.

These research objectives support the SLDAST RFA objectives [4]. 


\section{Simulation Setup}

This study used two software codes: Traffic Manager for the main simulation and AwSim for use in post-simulation analysis. A description of these is next, followed by a definition of the geographic region simulated and en route airspace volume for collection of data.

\section{Traffic Manager}

The approach for this study was to investigate the performance of Tactical ASAS using the Traffic Manager (TMX) air traffic simulation [5]. The National Aerospace Laboratory of the Netherlands (NLR) originally developed TMX and NASA Langley Research Center has made many enhancements.

TMX was developed for use in studies of aircraft-based concepts in future ATM environments. TMX can be used as one component of a real-time simulation in an airtraffic laboratory or as a stand-alone desktop simulation. This study used TMX as a standalone, non real-time simulator without any human in the loop interaction.

Currently, in stand-alone mode, TMX runs on a single workstation and can simulate up to 2000 airborne aircraft. This limits experiments to the scope of e.g. one ATC center at up to three times current demand levels. Figures 1 and 2 are screenshots of the TMX graphical user interface. 


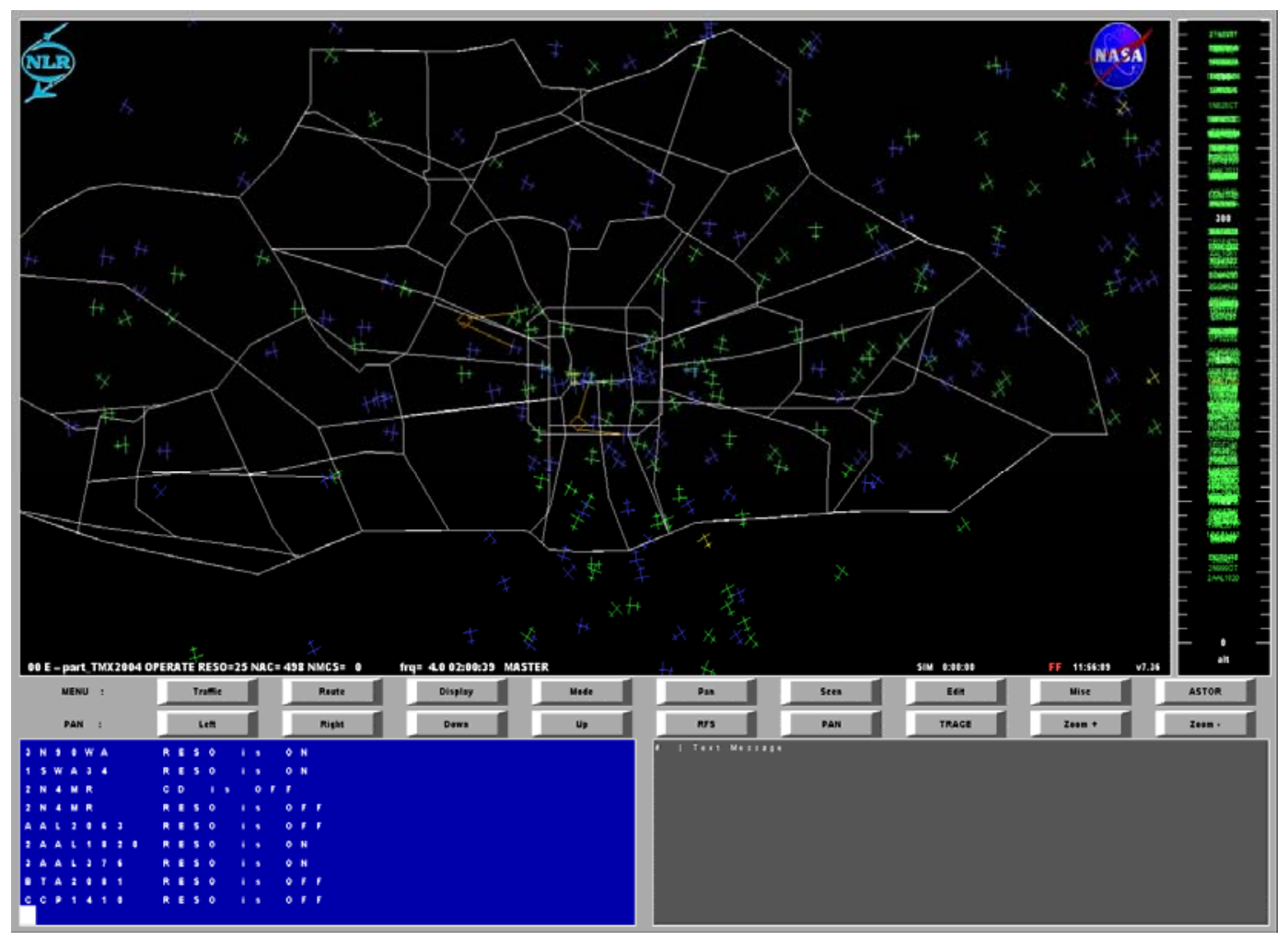

Figure 1. TMX user interface showing AFR aircraft (green) and IFR aircraft (blue).

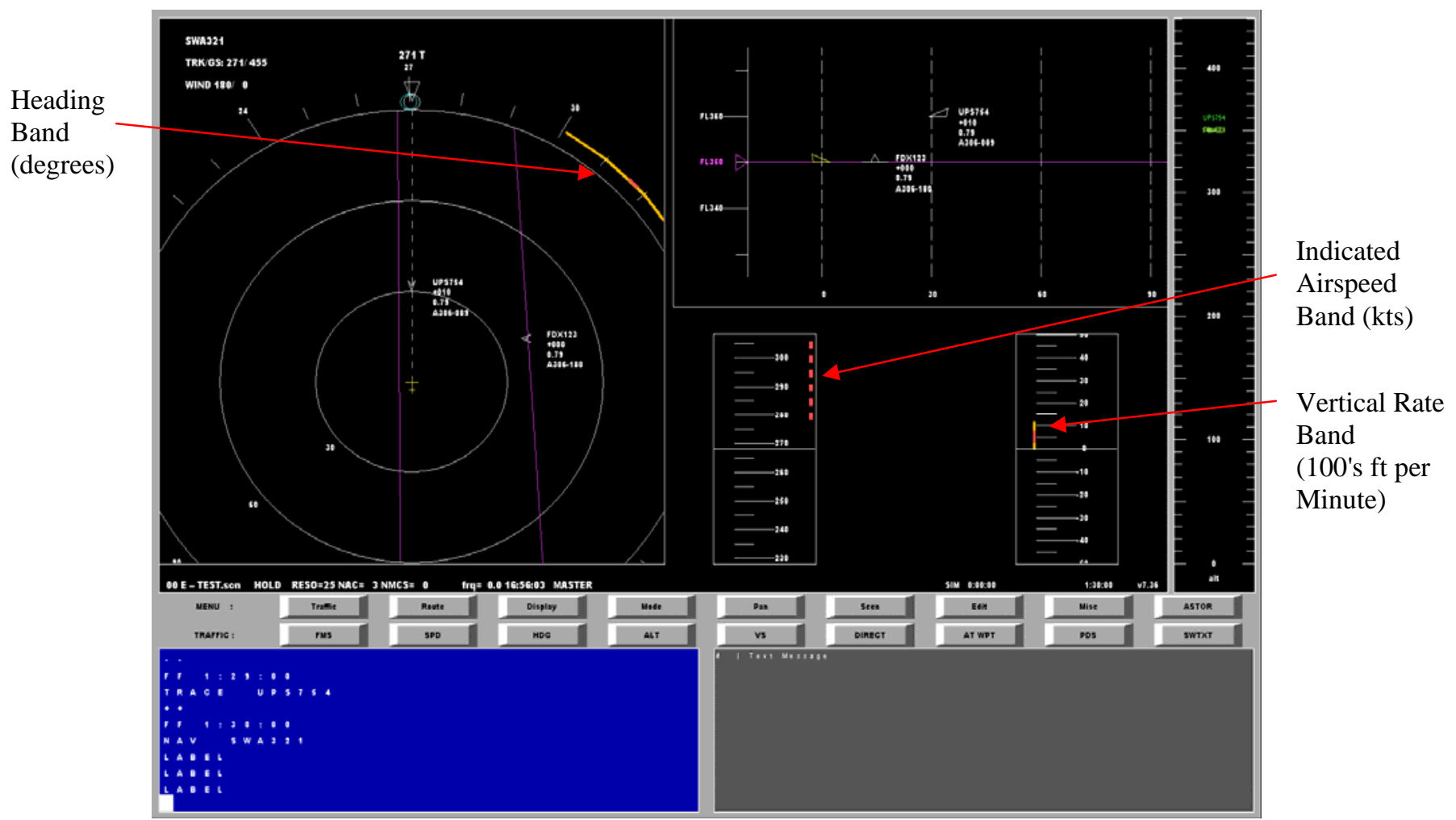

Figure 2. TMX conflict prevention bands for heading, speed and vertical rate.

(Yellow band indicates a predicted conflict within 5 minutes, red within 3 minutes.) 
TMX models aircraft performance and flight deck systems in detail, but does not have models of ground-based air traffic control or traffic flow management and does not limit airspace sector and airport capacity. For this study, the focus was on the en-route portion of the flight, from airport departure fix to airport arrival fix.

TMX uses an aircraft dynamics model with aircraft performance data from the Base of Aircraft Data (BADA) developed and maintained by the Eurocontrol Experimental Centre in Brétigny, France [6]. BADA uses a total energy model that is a reduced point-mass model that equates the rate of work done by forces acting on the aircraft to the rates of increase of potential and kinetic energy.

Input to this model comes from an operations performance model, which defines the mass, flight envelope, aerodynamics, engine thrust, and fuel consumption for common aircraft types. The BADA airline procedures model defines the speeds used during the climb, cruise and descent flight phases.

All aircraft within TMX may be equipped with some or all of:

- auto-flight functionality

- 4D Flight Management System (FMS)

- RTA meeting capability

- ADS-B

- $\mathrm{CD} \& \mathrm{R}$

- P-ASAS

The effect of wind is included and there is a model for pilot reaction time and scheduling effects. TMX has the capability to include randomized errors for all modeled systems, including wind measurement and prediction errors. For this study, there were no system or wind errors.

\section{CD\&R Algorithm}

The KB3D CD\&R algorithm was implemented within TMX for use in this study. KB3D is a tactical, state-based CD\&R algorithm developed in the Safety Critical Avionics Systems Branch at NASA Langley Research Center [7].

The KB3D algorithm provides one or more horizontal and vertical resolutions by calculating analytical solutions using linear trajectory projections. KB3D considers two aircraft in conflict, solving the most urgent conflict first. Resolutions are independent, so only one aircraft needs to maneuver and resolutions are coordinated so both aircraft can maneuver.

An advantage of an analytic approach is that the underlying math is amenable to formal proof of correctness. This allowed the mathematical properties of KB3D to be extensively studied and formalized in the Prototype Verification System (PVS) [8]. Formal proof using PVS guarantees that the algorithm will provide a resolution; however, KB3D does not check the resolution maneuvers for physical feasibility. 
Since KB3D does not take into account other aircraft when calculating resolutions for an aircraft pair, it is possible for resolutions to create additional secondary conflicts. The conflict prevention system helps the pilot avoid such conflicts.

In addition, KB3D does not check the resolution maneuvers for physical feasibility. This means that a resolution maneuver may call for turn rates, speed changes or vertical rates that the aircraft is not capable of performing.

If an aircraft cannot fully execute the resolution maneuver, it may not be possible to resolve the conflict in time to avoid loss of separation (LoS). This should occur infrequently; calculation of the minimal resolution maneuver required is an objective of the algorithm design.

\section{Flight Priority Rules}

Priority rules are used to establish right of way for one aircraft, so normally only one aircraft is required to maneuver when a conflict is detected. The resolution maneuvers provided by KB3D will solve the conflict if only one aircraft maneuvers, since they are independent. The advantage of using such rules is to avoid disruption to the planned trajectory of the aircraft with priority. This increases the efficiency of flight for that aircraft.

However, in the event that a short-term conflict is detected, both aircraft maneuver. This will also solve the conflict, since KB3D provides coordinated resolution maneuvers. The purpose here is to solve the conflict sooner, by having both aircraft take avoiding action.

These are the priority rules used for this study:

1. IFR aircraft have priority over AFR aircraft.

2. Aircraft that are more maneuverable have to give priority to less maneuverable aircraft, based on maneuver categories.

3. Level aircraft have priority over climbing and descending aircraft.

4. Descending aircraft have priority over climbing aircraft.

5. If two aircraft are in the same flight phase, the overtaking aircraft should give priority. An aircraft is considered to be overtaking if it is closing from an aspect angle between 150 to 210 degrees of another aircraft.

6. If none of the above applies, priority is allocated based on aircraft call sign.

\section{Pilot Model}

The TMX pilot model implements some decision-making, based on rules, to emulate the choices made by a human pilot when presented with resolution maneuver options. The pilot model also includes human reaction times that vary depending on the urgency of the situation. These may be randomized, but fixed values were used for this study. 
Given a choice of resolution, the pilot (or pilot model within TMX) needs to consult the PASAS conflict prevention system and select a maneuver that does not create additional secondary conflicts. Currently P-ASAS distinguishes between short-term conflicts (three minutes to predicted LoS) and long-term conflicts (five minutes to LoS).

These are the decision rules:

1. Select a heading resolution if the vertical resolution steers into a conflict prevention band.

2. Select a vertical resolution if the heading resolution steers into a conflict prevention band.

3. Select the maneuver that results in a long-term secondary conflict, if available, when both resolution directions steer into a conflict prevention band.

4. Do nothing when the primary conflict is a long-term conflict and both resolutions directions steer into a short-term secondary conflict.

5. When the time to LoS is within thirty seconds perform both lateral and vertical resolutions simultaneously.

These are the pilot reaction times:

1. Thirty seconds for a long-term conflict.

2. Ten seconds for a short-term conflict.

3. Five seconds for a secondary conflict.

After selecting a maneuver, the pilot model waits for 150 seconds after resolving the conflict before returning to planned trajectory. This helps prevents re-occurrence of a conflict with the same aircraft.

\section{AwSim}

A trajectory analysis program, AwSim [9], was used to assist with the results evaluation. AwSim is a suite of trajectory simulation, conflict prediction, and metrics tools designed to perform a variety of air traffic simulation and evaluation tasks. Amongst other capabilities, this program allows visualization of recorded flight trajectories. A plan view of the NAS is supplemented by altitude profile information. AwSim has controls for fast-forward, rewind, pause and step forward or backward in time.

\section{Region of Study}

The airspace region used for this study is Fort Worth Center (ZFW) (see figure 3). All aircraft departing from, flying through or landing within ZFW are included in the simulation. Figure 4 shows the notional elevation view of the en route airspace defined for this experiment, with altitude bounds from 17,000 ft to 60,000 ft. The CD\&R and P-ASAS 
systems were functional from departure, through transition into the experiment volume and then turned off as aircraft exit from the experiment volume. Flights were deleted from the simulation as they descended through $5000 \mathrm{ft}$.

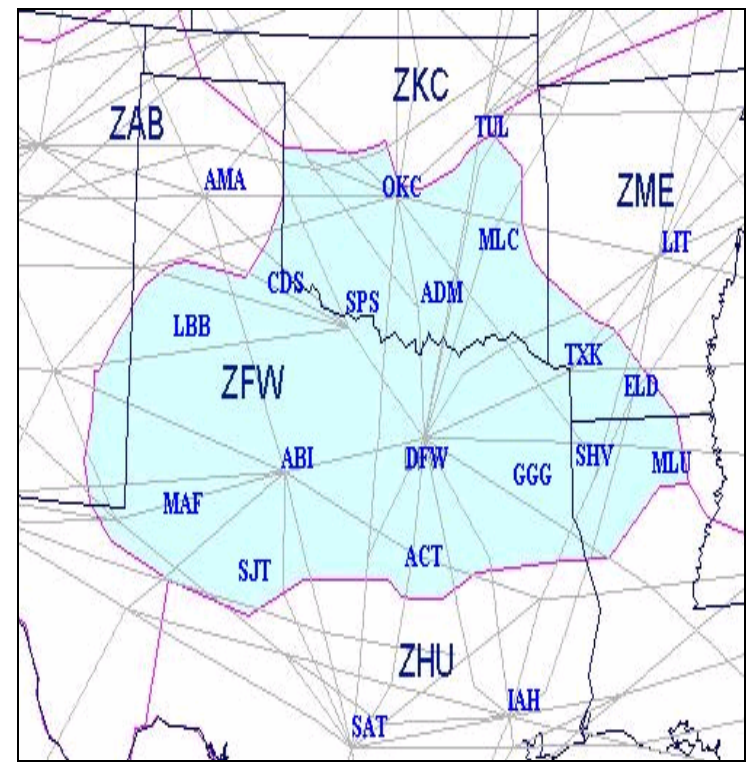

Figure 3. Fort Worth Center airspace.

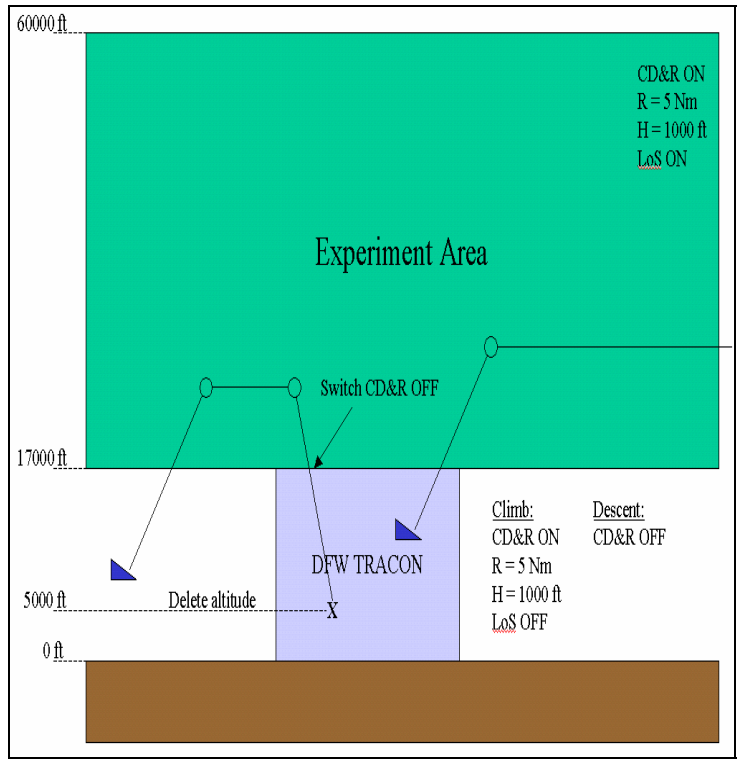

Figure 4. Experiment airspace. 


\section{Flight Data Sets}

The flight trajectories that were recorded by the Enhanced Traffic Management System (ETMS) on 19 February 2004 form the basis for the flight data sets used in this study. This day is one of the JPDO baseline traffic days, representing a typical day in the NAS with good weather and moderately high traffic flow. Thus, simulated traffic flows are realistic, based on actual recorded data. The simulated traffic flows retain the complexity of the traffic flows within ZFW center.

The study flight data sets consisted of IFR-only, AFR-only and mixed scenarios and range from one to three times current demand levels. The increased demand levels were created by copying the baseline-recorded trajectories and rescheduling as described below. Table 1 shows the number of flights in each of the data sets.

\begin{tabular}{|l|r|r|r|r|r|r|}
\hline & $\begin{array}{c}\text { IFR } \\
\text { baseline } \\
\text { schedule }\end{array}$ & 1X AFR & 2X AFR & 3X AFR & $\begin{array}{c}\text { 1X IFR } \\
+\end{array}$ & $\begin{array}{c}\text { 1X IFR } \\
+ \\
\text { 2X AFR }\end{array}$ \\
\hline Total flights & 4,079 & 4,079 & 8,158 & 12,237 & 8,158 & 12,237 \\
\hline
\end{tabular}

Table 1. Flight data sets used in simulation.

The IFR flights use the as-flown trajectories that were derived from the ETMS radar track data (TZ) messages. The IFR flight schedule is almost exactly as flown, with slight adjustments in departure times; these were made as necessary to ensure a minimum spacing of 70 seconds between aircraft arriving at the same arrival fix. This time spacing ensures in-trail separations are approximately $5 \mathrm{~nm}$.

The AFR flights are based on the same ETMS data converted to great-circle routes. AFR flights are also scheduled to meet 70 seconds spacing at the arrival fix. AFR flights flew fuel-optimal trajectories based on BADA performance data and were not constrained by the current cardinality rules for flight altitude levels.

For the mixed flight schedules, AFR flights were inserted into gaps in the IFR arrivals streams at each fix to maintain a minimum of 70 seconds spacing.

The use of 70 seconds spacing ensures that the minimum distance between aircraft at the airport arrival fixes is approximately five nm. For simplicity of scheduling, generic arrival fixes replace the actual arrival fixes for both IFR and AFR flights. Four generic fixes are equally spaced on a $40 \mathrm{~nm}$ radius circle centered on each airport. This four-corner post arrangement is close to the actual fix arrangement used by many airports (an example is DFW).

Scripted conflicts were not included in this experiment. Rather, all aircraft departed their origin airports at their nominal time to meet their RTA at the arrival fixes. Conflicts developed naturally without pre-determination. The result is that the ASAS system is subjected to a full range of traffic situations and geometries that ranged from simple to quite complex. The experiment was therefore a blind test of whether the conflict management algorithms and procedures were robust to all of the conditions that were encountered. 


\section{Results}

The flight data sets described previously were used as input to TMX for simulation of 24 hours worth of NAS operations. Simulation of a complete day captures the peaks and troughs in demand that typically occur.

The results presented below were obtained from simulations that employed error-free surveillance data. The simulation test cases used actual wind data from 19 February 2004, without errors between actual and predicted winds.

The modeling included aircraft dynamic performance, with error-free FMS performance. Pilot response times were included, but were not randomized. TMX has the ability to include randomized errors for all modeled systems, including wind measurement and prediction errors; the performance of ASAS with realistic errors is the subject of on-going and future research.

The results analysis is organized into the following sections: first, traffic densities; next, conflicts and losses of separation; finally, flight efficiency.

\section{Traffic Densities}

Table 2 shows various measures of traffic density in the simulation. By design, the 24-hour demand was twice and three times the baseline. The number of aircraft airborne at any time varies according to the schedule and the peak does not reach exactly twice and three times the demand. The peak flight density multiplier is somewhat less than the $2 \mathrm{X}$ and $3 \mathrm{X}$ input demand because flights are re-scheduled to ensure a minimum of 70 seconds between aircraft at the airport arrival fixes.

\begin{tabular}{|c|c|c|c|c|c|}
\hline & \multirow{2}{*}{$\begin{array}{c}\text { IFR } \\
\text { baseline } \\
\text { schedule }\end{array}$} & \multicolumn{2}{|c|}{ 2X AFR } & \multicolumn{2}{|c|}{ 3X AFR } \\
\hline & & Flights & $\begin{array}{c}\text { Multiple } \\
\text { of baseline }\end{array}$ & Flights & $\begin{array}{l}\text { Multiple } \\
\text { of baseline }\end{array}$ \\
\hline $\begin{array}{l}\text { Total flights } \\
\text { in } 24 \mathrm{hrs}\end{array}$ & 4,079 & 8,158 & $2 X$ & 12,237 & $3 \mathbf{X}$ \\
\hline $\begin{array}{l}\text { Peak flights in } \\
\text { simulation }\end{array}$ & 516 & 1,035 & $2 X$ & 1,519 & 2.9X \\
\hline Peak flights ZFW & 126 & 241 & $1.9 X$ & 326 & $2.6 X$ \\
\hline $\begin{array}{l}\text { Mean flights ZFW in } \\
24 \text { hrs }\end{array}$ & 61 & 114 & $1.9 X$ & 171 & $2.8 X$ \\
\hline
\end{tabular}

Table 2. Number of aircraft in the simulation.

The busiest sector within ZFW was ZFW4201 High sector. This sector had a maximum count of 46 aircraft simultaneously in the sector for the $3 \mathrm{X}$ demand compared with 17 for the baseline number of airborne aircraft. This is well in excess of the current maximum capacity of 20 aircraft set by the monitor alert parameter (MAP) value (see figure 5). FAA traffic flow managers compare the projected number of aircraft in a sector with the MAP value to determine if a sector is likely to be overloaded. 


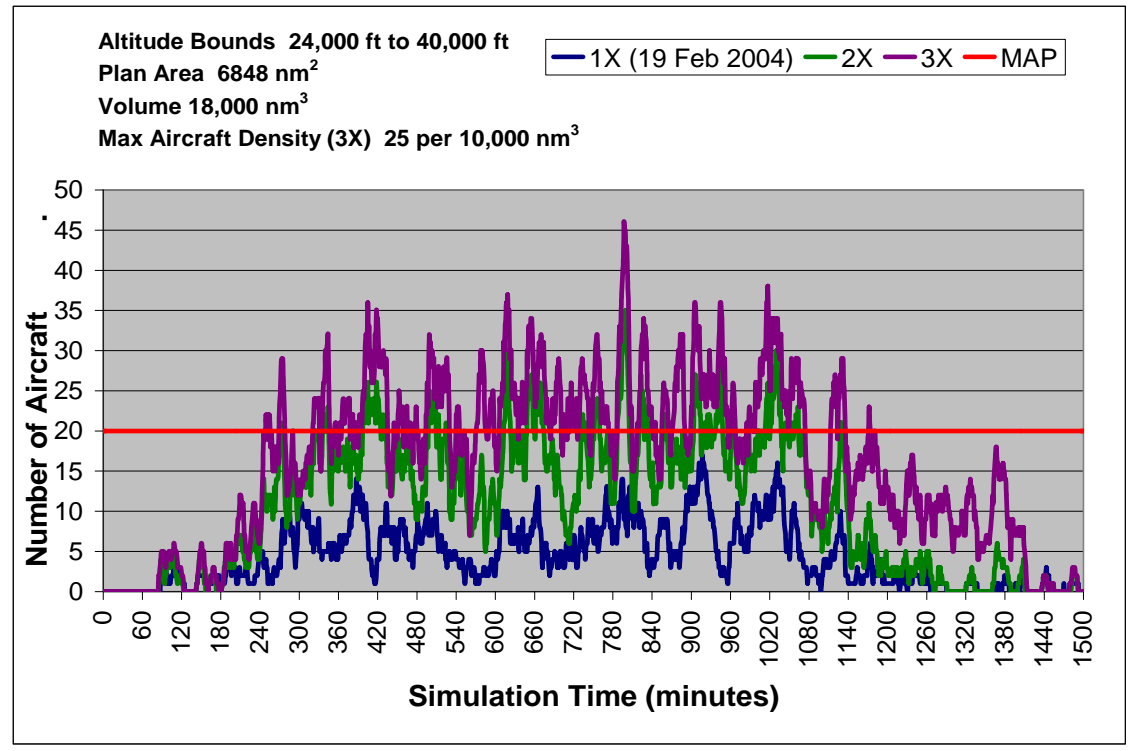

Figure 5. Number of aircraft in busiest ZFW sector (ZFW4201 High).

A discussion of Tactical ASAS performance follows in the next sections, in terms of conflicts and losses of separation and efficiency of flight. Note, however, that traffic densities outside of ZFW center are less than the actual traffic densities because not all flights in the NAS could be included in the simulation. For this reason, conflict data was analyzed within the experiment volume only. Data outside of the experiment volume does not represent the performance of Tactical ASAS at full traffic densities. Likewise, efficiency data is interpreted with the caveats stated in the relevant section.

\section{Conflicts and Losses of Separation}

The terms used and values of key parameters are presented prior to discussion of results.

Definitions of terms are:

- Conflict: a predicted loss of separation within a given look-ahead time (One pair of aircraft in conflict count as two conflicts).

- IFR to AFR Conflicts: conflicts detected first by IFR aircraft

- AFR to IFR Conflicts: conflicts detected first by AFR aircraft

- LoS: Loss of Separation (One pair of aircraft count as one loss).

- CPA: Closest Point of Approach between an aircraft and any other.

The criteria used to report a LoS are:

- Aircraft closer than $5 \mathrm{~nm}$ lateral distance and $900 \mathrm{ft}$ altitude, for more than 10 seconds duration.

The protected zone around an aircraft to detect a conflict is:

- AFR to AFR: $5.1 \mathrm{~nm}$ lateral, $950 \mathrm{ft}$ altitude at 300 seconds look-ahead time.

- AFR to IFR: $6.1 \mathrm{~nm}$ lateral, 1,150 ft altitude at 300 seconds look-ahead time.

- IFR to AFR: $5.1 \mathrm{~nm}$ lateral, $950 \mathrm{ft}$ altitude at 180 seconds look-ahead time. 
The zone around an aircraft for conflict resolution is:

- AFR to AFR: $5.2 \mathrm{~nm}$ lateral, $1100 \mathrm{ft}$ altitude at 300 seconds look-ahead time.

- AFR to IFR: $6.2 \mathrm{~nm}$ lateral, $1300 \mathrm{ft}$ altitude at 300 seconds look-ahead time.

Notes:

1. The conflict resolution zone was larger than the protected zone to allow some uncertainty buffer, increasing the probability that the conflict would be resolved by the resolution maneuver.

2. A larger protected zone between AFR to IFR aircraft and a longer look-ahead time relative to IFR to AFR was used. The intent was that the AFR aircraft would detect and resolve the conflict with the IFR aircraft before the ground controller was alerted to the impending conflict.

3. The vertical separation minima is $900 \mathrm{ft}$ rather than the current vertical separation minima of $1000 \mathrm{ft}$, since aircraft may be up to $100 \mathrm{ft}$ from assigned altitude due to allowable altimeter inaccuracy.

Table 3 summarizes the results obtained from analysis of data logged by TMX within the experiment volume described in the experiment set up section.

\begin{tabular}{|c|r|r|r|r|r|r|}
\hline $\begin{array}{c}\text { ETMS } \\
\text { based }\end{array}$ & $\begin{array}{c}\text { 1X IFR } \\
\text { (from } \\
\text { ETMS) }\end{array}$ & 1X AFR & 2X AFR & 3X AFR & $\begin{array}{r}\text { 1X IFR + } \\
\text { 1X AFR }\end{array}$ & $\begin{array}{r}\text { 1X IFR + } \\
\text { 2X AFR }\end{array}$ \\
\hline Flights & 4,079 & 4,079 & 8,158 & 12,237 & 8,158 & 12,237 \\
\hline Conflicts & NA/ & 1,021 & 4,155 & 9,257 & 4,751 & 12,228 \\
\hline $\begin{array}{c}\text { IFR_AFR } \\
\text { conflicts }\end{array}$ & NA/ & N/A & N/A & N/A & 628 & 1,144 \\
\hline $\begin{array}{c}\text { Number of } \\
\text { LoS }\end{array}$ & N/A & 0 & 3 & 25 & 26 & 58 \\
\hline $\begin{array}{c}\text { Resolved } \\
\text { Conflicts } \\
\text { (\%) }\end{array}$ & N/A & $100.0 \%$ & $99.9 \%$ & $99.5 \%$ & $98.9 \%$ & $99.1 \%$ \\
\hline
\end{tabular}

Table 3. Conflicts and losses of separation within experiment volume.

The results show that Tactical ASAS, using the KB3D CD\&R algorithm, in combination with P-ASAS can prevent all losses of separation for the $1 \mathrm{X}$ demand scenario if all aircraft are AFR flights. For the $2 \mathrm{X}$ AFR scenario, one of the three LoS is attributable to Tactical ASAS. The LoS was of short duration with a separation of $4.5 \mathrm{~nm}$ at the CPA. The other two LoS are caused by an experiment set up issue that is discussed in the next section.

The number of LoS increases for the $3 \mathrm{X}$ AFR scenario. However, all but four of the LoS had a CPA larger than $3 \mathrm{~nm}$. The closest encounter had a CPA of $0.18 \mathrm{~nm}$, but in this case, the vertical separation was $818 \mathrm{ft}$, which is just under the $900 \mathrm{ft}$ vertical separation criteria used for this study. 
The mixed $1 \mathrm{X}$ IFR + 1X AFR case has many IFR to AFR conflicts. Note that this would require the IFR aircraft to take action to avoid the AFR aircraft, which is contrary to the concept design. In addition, considerably more losses of separation occurred compared with the all-AFR scenario with the same $2 \mathrm{X}$ demand.

The mixed $1 \mathrm{X}$ IFR $+2 \mathrm{X}$ AFR case has one-third more conflicts and more than twice as many losses of separation than the all-AFR case at the same $3 \mathrm{X}$ demand level.

The causes for many of the LoS are understood; discussion of causes and some suggestions for improving the performance of Tactical ASAS follows.

\section{Analysis of Loss of Separation}

The AwSim trajectory analysis tool assists visualization of the actual flown trajectories recorded during TMX simulation. The recorded trajectories include all conflict resolution maneuvers. Visualization viewed alongside additional data logged by TMX, facilitates understanding of the cause of the LoS.

\section{Discussion of Causes of Loss of Separation}

The list below identifies the causes of the LoS for the 2X AFR, 3X AFR and the $1 \mathrm{X}$ AFR $+1 \mathrm{X}$ IFR scenarios and the number of cases that are attributed to each cause. (The $1 \mathrm{X}$ AFR + 2X AFR scenario has not been analyzed in detail.) Note that a LoS may have more than one cause.

\section{AFR aircraft maneuvers into short-term conflict (24 LoS)}

The conflict prevention system should prevent maneuvers that result in conflicts with predicted LoS in less than three minutes. This was not always the case, particularly with climbing and descending aircraft. P-ASAS assumes linear trajectory propagation and linear climb and descent profiles. Actual aircraft may be changing speed or heading and often do not climb or descend linearly. Aircraft in the simulation above 18,000 ft are climbing or descending at constant Mach. Since groundspeed reduces with altitude at constant Mach (in the troposphere), this results in a flight path that curves in the vertical Cartesian plane. In addition, an aircraft climbs more slowly near its maximum altitude limit. For these reasons, PASAS may incorrectly predict aircraft trajectory, leading to incorrect conflict bands.

Aircraft sometimes maneuver into short-term conflict for a different reason; the pilot model occasionally selects resolution maneuvers that contradict the P-ASAS conflict prevention system. In some circumstances, this problem is unavoidable, because conflict bands may indicate that all resolution maneuvers provided by $\mathrm{KB} 3 \mathrm{D}$ result in a secondary conflict.

\section{CD\&R and P-ASAS inactivated below $17,000 \mathrm{ft}(16$ Los)}

The experiment was purposely set up to turn off CD\&R and P-ASAS below 17,000 $\mathrm{ft}$, because the concept studied is for en route airspace. Once turned off, CD\&R and 
P-ASAS are not turned on again. Thus, an unintended side effect results where one aircraft descends below the boundary and then levels off into a short-term conflict. An aircraft can likewise descend below the boundary during the climb phase of flight because of a conflict maneuver and then resume climbing above 17,000 ft and cause short-term conflicts throughout the remainder of the flight.

\section{Poor resolution choice (14 LoS)}

The pilot model is not sophisticated and can occasionally select a maneuver that is a poor choice or that takes the aircraft into an irretrievably complex situation. KB3D offers a choice of resolution maneuvers for the two aircraft in conflict, independent of the trajectories of other aircraft; the human pilot, supported by PASAS selects the most appropriate resolution.

\section{KB3D fails to predict a conflict in time to prevent LoS (11 LoS)}

KB3D sometimes detects a conflict with fewer than three minutes to LoS. In a few cases, only seconds remained before LoS, which is too short a time to resolve the conflict. This problem occurs mainly with climbing and descending aircraft. The KB3D algorithm assumes linear trajectory propagation and linear climb and descent profiles. For the same reasons as explained for cause 1, this can lead to inaccurate prediction of the aircraft trajectory. Consequently, prediction error can cause KB3D to detect conflicts too late to prevent a LoS.

5. KB3D does not continue to provide resolutions once aircraft are in LoS (6 LoS)

The current design of KB3D does not calculate resolutions if the aircraft in conflict move into LoS. This problem can prolong the LoS, lead to a closer encounter and potentially lead to a further LoS with additional aircraft. For AFR to IFR cases where a $6 \mathrm{~nm}$ protected zone is used, KB3D stops providing resolutions once the aircraft are closer than the $6 \mathrm{~nm}$ protected zone even though the separation criteria for LoS have not been violated. This is because KB3D does not currently distinguish between an additional buffer zone and the actual separation criteria.

\section{IFR aircraft maneuvers into short-term conflict with AFR (6 LoS)}

The simulated IFR aircraft currently fly ETMS recorded trajectories. No mechanism is included in the simulation to prevent IFR aircraft from creating short-term conflicts.

\section{KB3D does not take into account aircraft performance (3 LoS)}

While geometrically correct, KB3D may provide a resolution maneuver that is beyond the capabilities of the aircraft. The aircraft may not be able to respond quickly enough, or the speed or the requested altitude may not be feasible. The resolution maneuver may sometimes require an aircraft to climb when it is near the aircraft altitude ceiling 
The most common cause of LoS was a failure to prevent an AFR heading or altitude change from causing a short-term conflict. This cause may be due to a failure of the PASAS system to predict conflict bands accurately or a failure of the pilot model to consider the bands.

Currently, TMX uses a geometric calculation for predicting conflict bands, similar but not the same as the KB3D algorithm uses for conflict resolution. This can be replaced by a KB3D-based system to determine conflict bands. This would be preferable for consistency with the resolution maneuvers. In addition, using realistic assumptions for climb and descent profiles can improve trajectory prediction. Using buffer zones that are larger for aircraft not in level flight can better account for uncertainty.

Improvements to the pilot model may prevent some of the LoS where the model selects a maneuver that fails to consider the conflict bands. An indication of the maneuver with the longest time to LoS could assist the human pilot in making a decision and facilitate a better simulation model.

The second most common cause is a problem with simulation set up; Tactical ASAS is turned off below 17,000 ft. The experiment set up problem will be fixed for future studies.

The third most common cause is a poor choice of resolution, which can be attributed to an unsophisticated pilot model. Given a choice of maneuver from KB3D, a human pilot may have avoided the LoS by selecting a better choice of resolution maneuver. Some measure of traffic complexity in the region of the proposed maneuver may facilitate a better choice of maneuver. This would enable the pilot model in a simulation to make a better choice and might be a useful aid to a human pilot who is using ASAS.

Solutions to the remaining causes of LoS are also under consideration. These include enhancements to KB3D to improve trajectory prediction and to continue providing resolutions for aircraft in LoS. Checking of resolutions for physical feasibility is an obvious enhancement e.g. for aircraft near their altitude ceiling a climb is not a good choice of resolution. In this case, a heading change or descent would be the better choice.

A version of KB3D that uses some knowledge of aircraft intent is being designed. Conflicts may reduce if a strategic component to ASAS is included; this should lead to a corresponding reduction in LoS.

Strategic ASAS cannot prevent all short-term conflicts that arise from unplanned maneuvers (e.g. for conflict resolution maneuvers, intent data may not be available). Therefore, in a mixed equipage environment controllers may be required to avoid vectoring IFR aircraft into short-term conflicts with AFR aircraft.

A discussion of the causes of LoS for each of the scenarios analyzed follows; tables 4, 5 and 6 present details of the LoS. 


\section{X AFR Scenario}

For the 2X AFR scenario, only the AAL1591/ AAL1638 LoS is attributable to ASAS because the other two LoS were caused by the problem with experiment setup. The AAL1591/ AAL1638 LoS was of short duration with a separation of nearly $4.5 \mathrm{~nm}$ at the CPA.

\begin{tabular}{|l|l|l|l|c|c|c|c|c|c|}
\hline \multicolumn{2}{|c|}{$\begin{array}{c}\text { Aircraft } \\
\text { ID }\end{array}$} & \multicolumn{2}{c|}{$\begin{array}{c}\text { Flight } \\
\text { Rules }\end{array}$} & $\begin{array}{c}\text { CPA } \\
\text { (nm) }\end{array}$ & $\begin{array}{c}\text { Dura- } \\
\text { tion } \\
\text { (sec) }\end{array}$ & $\begin{array}{c}\text { Alt. 1 } \\
\text { (ft) }\end{array}$ & $\begin{array}{c}\text { Alt. 2 } \\
\text { (ft) }\end{array}$ & $\begin{array}{c}\text { Alt. } \\
\text { Dif. } \\
\text { (ft) }\end{array}$ & Cause \\
\hline 1SWA1937 & 1CAA783 & AFR & AFR & 2.34 & 38 & 17926 & 17108 & 818 & 2 \\
\hline AAL1591 & AAL1638 & AFR & AFR & 4.47 & 16 & 25887 & 26177 & 290 & 4 \\
\hline 1N446M & N446M & AFR & AFR & 4.85 & 18 & 17368 & 16582 & 786 & 2 \\
\hline
\end{tabular}

Table 4. 2X AFR loss of separation

\section{X AFR Scenario}

For the 3X AFR scenario, two of the LoS were due to experiment setup. Four out of five of the LoS with smallest CPA were only just within the $900 \mathrm{ft}$ vertical separation standard. The likely cause is prediction inaccuracies, either in KB3D or P-ASAS or both.

If aircraft are vertically separated, this allows aircraft to become close in the horizontal dimension, so a small inaccuracy in vertical trajectory prediction can suddenly lead to a very short-term conflict. The reverse is also true, but the consequences are less severe, since the horizontal separation standard is more than six times larger than the vertical separation standard. 


\begin{tabular}{|c|c|c|c|c|c|c|c|c|c|}
\hline \multicolumn{2}{|c|}{$\begin{array}{c}\text { Aircraft } \\
\text { ID }\end{array}$} & \multicolumn{2}{|c|}{$\begin{array}{l}\text { Flight } \\
\text { Rules }\end{array}$} & \multirow{2}{*}{$\begin{array}{c}\begin{array}{c}\text { CPA } \\
(\mathbf{n m})\end{array} \\
0.18 \\
\end{array}$} & \multirow{2}{*}{$\begin{array}{c}\begin{array}{c}\text { Dura- } \\
\text { tion } \\
\text { (sec) }\end{array} \\
36\end{array}$} & \multirow{2}{*}{$\begin{array}{c}\begin{array}{c}\text { Alt. } 1 \\
\text { (ft) }\end{array} \\
34888\end{array}$} & \multirow{2}{*}{$\begin{array}{c}\begin{array}{c}\text { Alt. } 2 \\
\text { (ft) }\end{array} \\
34000 \\
\end{array}$} & \multirow{2}{*}{$\begin{array}{c}\begin{array}{c}\text { Alt. } \\
\text { Dif. (ft) }\end{array} \\
888 \\
\end{array}$} & \multirow{2}{*}{$\begin{array}{r}\text { Cause } \\
1,3 \\
\end{array}$} \\
\hline 2SWA440 & 1NWA1857 & AFR & AFR & & & & & & \\
\hline AWE7815 & 2AWE7815 & AFR & AFR & 1.20 & 82 & 34111 & 35000 & 889 & 1 \\
\hline 1COA1153 & 1SKW9519 & AFR & AFR & 1.40 & 122 & 28820 & 29428 & 608 & 1,3 \\
\hline 1CXP213 & 5TRS103 & AFR & AFR & 2.77 & 56 & 35115 & 36000 & 885 & 1 \\
\hline AWE664 & 1DAL463 & AFR & AFR & 3.11 & 32 & 35000 & 35866 & 866 & 1 \\
\hline 2N183PC & $6 \mathrm{~N} 560 \mathrm{KT}$ & AFR & AFR & 3.37 & 16 & 25195 & 24733 & 462 & 1 \\
\hline 1AAL791 & 2BTA2190 & AFR & AFR & 3.52 & 12 & 38042 & 37184 & 858 & 1 \\
\hline 2N213CC & N698PW & AFR & AFR & 3.54 & 38 & 21417 & 21106 & 311 & $1,3,4$ \\
\hline 2BKA535 & 5BKA535 & AFR & AFR & 3.55 & 82 & 22718 & 21834 & 884 & 4 \\
\hline N1903G & 3N1903G & AFR & AFR & 3.80 & 72 & 40360 & 40000 & 360 & 3,7 \\
\hline 2N421NL & 1N421NL & AFR & AFR & 3.93 & 46 & 23000 & 23294 & 294 & 3,4 \\
\hline N520E & 1N520E & AFR & AFR & 4.06 & 52 & 20273 & 20725 & 452 & $1,3,4$ \\
\hline 1AAL1625 & 2AAL1625 & AFR & AFR & 4.30 & 146 & 23847 & 22952 & 895 & 1,4 \\
\hline 1SWA1939 & 1N738K & AFR & AFR & 4.39 & 20 & 28963 & 28364 & 599 & $1,3,4$ \\
\hline 3N904SB & 4CAA863 & AFR & AFR & 4.41 & 28 & 18407 & 18312 & 95 & 2 \\
\hline AAL1194 & SWA675 & AFR & AFR & 4.48 & 12 & 40266 & 40000 & 266 & 1 \\
\hline AAL2851 & AAL1663 & AFR & AFR & 4.49 & 12 & 19628 & 19169 & 459 & 2 \\
\hline 1N60RE & 1AMW2628 & AFR & AFR & 4.54 & 46 & 19397 & 18532 & 865 & 2 \\
\hline BKA535 & 7BKA535 & AFR & AFR & 4.58 & 30 & 26881 & 25994 & 887 & 3 \\
\hline CHQ5827 & 2CHQ5827 & AFR & AFR & 4.61 & 12 & 36001 & 35742 & 259 & 1,3 \\
\hline UAL372 & 2UAL372 & AFR & AFR & 4.65 & 16 & 38000 & 38163 & 163 & 1,3 \\
\hline AAL840 & 2AAL1505 & AFR & AFR & 4.69 & 14 & 36007 & 36000 & 7 & 1 \\
\hline 2CAA511 & 2AAL1255 & AFR & AFR & 4.72 & 18 & 20022 & 19607 & 415 & 1,4 \\
\hline 1COA1289 & 2COA1289 & AFR & AFR & 4.84 & 16 & 36097 & 36000 & 97 & 1 \\
\hline EGF553 & 1EGF553 & AFR & AFR & 4.88 & 12 & 21000 & 20385 & 615 & 1 \\
\hline
\end{tabular}

Table 5. 3X AFR loss of separation

\section{X AFR + 1X IFR Scenario}

For the $1 \mathrm{X}$ AFR + 1X IFR mixed equipage scenario, the following LoS categories are used:

- AFR to AFR

- AFR to IFR

- IFR to AFR

For the mixed cases, the order indicates which aircraft detected the conflict first.

Only two AFR to AFR LoS occurred, of which only 1DAL730/ 2N49CT is attributable to Tactical ASAS. This LoS results from a complex encounter and likely has multiple causes.

Of the AFR to IFR LoS, the cause of six of the fourteen is an IFR aircraft maneuvering into short-term conflict with the AFR. This may indicate a need for the air traffic controller to be aware of the AFR aircraft and avoid vectoring IFR aircraft into a short-term conflict. Knowledge of the short-term intent of IFR aircraft by ASAS would likely avoid some of these LoS, but not all. 
Since the protected zone and look-ahead time for conflict prediction is larger between AFR to IFR than for IFR to AFR, then IFR to AFR LoS should not have occurred. In fact, all of the ten LoS that occurred in this category are due to the simulation setup problem (item 2 in the list of causes of LoS) and are not attributable to Tactical ASAS.

\begin{tabular}{|c|c|c|c|c|c|c|c|c|c|}
\hline \multicolumn{2}{|c|}{$\begin{array}{l}\text { Aircraft } \\
\text { ID }\end{array}$} & \multicolumn{2}{|c|}{$\begin{array}{l}\text { Flight } \\
\text { Rules }\end{array}$} & \multirow{2}{*}{$\begin{array}{c}\begin{array}{l}\text { CPA } \\
\text { (nm) }\end{array} \\
1.68\end{array}$} & \multirow{2}{*}{$\begin{array}{c}\begin{array}{c}\text { Dura- } \\
\text { tion } \\
\text { (sec) }\end{array} \\
176\end{array}$} & \multirow{2}{*}{$\begin{array}{c}\begin{array}{c}\text { Alt. } 1 \\
\text { (ft) }\end{array} \\
40715\end{array}$} & \multirow{2}{*}{$\begin{array}{c}\begin{array}{c}\text { Alt. } 2 \\
\text { (ft) }\end{array} \\
40267\end{array}$} & \multirow{2}{*}{$\begin{array}{c}\begin{array}{c}\text { Alt. } \\
\text { Dif. (ft) }\end{array} \\
448\end{array}$} & \multirow{2}{*}{$\begin{array}{l}\text { Cause } \\
3,4,5,7\end{array}$} \\
\hline 1DAL730 & 2N49CT & AFR & AFR & & & & & & \\
\hline 3SWA143 & 1CAA586 & AFR & AFR & 4.11 & 30 & 17233 & 16373 & 860 & 2 \\
\hline 1SKW3728 & N390DP & AFR & IFR & 2.14 & 48 & 38011 & 37945 & 66 & 3,4 \\
\hline 2DAL1687 & UAL1293 & AFR & IFR & 2.64 & 48 & 31270 & 31000 & 270 & 1,7 \\
\hline 1AAL888 & EGF469 & AFR & IFR & 2.91 & 36 & 29313 & 29000 & 313 & 5,6 \\
\hline 1AAL420 & AAL2347 & AFR & IFR & 3.44 & 16 & 28413 & 29050 & 637 & 5,6 \\
\hline 2CAA610 & N698PW & AFR & IFR & 3.47 & 240 & 21108 & 22000 & 892 & 1,5 \\
\hline 1EGF535 & EGF535 & AFR & IFR & 3.75 & 64 & 19745 & 20456 & 711 & 5,6 \\
\hline 1AAL323 & 1DAL2088 & AFR & IFR & 3.75 & 12 & 24333 & 25142 & 809 & 6 \\
\hline 1PCE252 & SWA1073 & AFR & IFR & 4.02 & 44 & 38348 & 39000 & 652 & 1,3 \\
\hline 3AAL743 & VPBDJ & AFR & IFR & 4.18 & 30 & 26315 & 27000 & 685 & 1 \\
\hline 2N81432 & AAL1163 & AFR & IFR & 4.26 & 48 & 29788 & 30675 & 887 & 6 \\
\hline 1BTA3305 & JOSA614 & AFR & IFR & 4.59 & 38 & 35210 & 35000 & 210 & 3 \\
\hline 2AAL1191 & AAL1916 & AFR & IFR & 4.60 & 80 & 20318 & 20780 & 462 & 1,4 \\
\hline 2N650LR & 1N650LR & AFR & IFR & 4.80 & 42 & 19258 & 19000 & 258 & 1,5 \\
\hline 4JOSA453 & 2AJI5 & AFR & IFR & 4.90 & 28 & 20393 & 20805 & 412 & 6 \\
\hline 1SWA43 & 2SWA43 & IFR & AFR & 0.91 & 32 & 17042 & 16441 & 601 & 2 \\
\hline 1SWA36 & 2N568WC & IFR & AFR & 1.76 & 84 & 17067 & 17095 & 28 & 2 \\
\hline 1EGF796 & 2EGF796 & IFR & AFR & 2.11 & 12 & 19299 & 18498 & 801 & 2 \\
\hline AAL745 & 1AAL745 & IFR & AFR & 2.26 & 26 & 18120 & 17286 & 834 & 2 \\
\hline N427CD & 1AAL745 & IFR & AFR & 2.45 & 32 & 18269 & 17428 & 841 & 2 \\
\hline 1AAL2846 & 1SWA340 & IFR & AFR & 2.48 & 196 & 17053 & 17018 & 35 & 2 \\
\hline FDX3004 & 3EJA782 & IFR & AFR & 3.04 & 72 & 31224 & 32118 & 894 & 2 \\
\hline EJA782 & 3EJA782 & IFR & AFR & 3.54 & 40 & 17909 & 17011 & 898 & 2 \\
\hline SWA40 & 1EGF526 & IFR & AFR & 4.16 & 26 & 17824 & 17027 & 797 & 2 \\
\hline AAL1023 & 3EJA782 & IFR & AFR & 4.52 & 24 & 28522 & 29409 & 887 & 2 \\
\hline
\end{tabular}

Table 6. 1X AFR plus 1X IFR mixed equipage loss of separation 


\section{Detailed Analysis of Three Selected Loss of Separation}

The figures in the following analysis are screen shots from the AwSim trajectory analysis program. The aircraft data block in the figures below shows aircraft identifier, altitude and ground speed. Aircraft circle radius is $2.5 \mathrm{~nm}$ in all figures, so overlapping circles indicate a LoS, if altitude separation is less than $900 \mathrm{ft}$.

\section{X AFR Scenario}

\section{SWA440 and 1NWA1857}

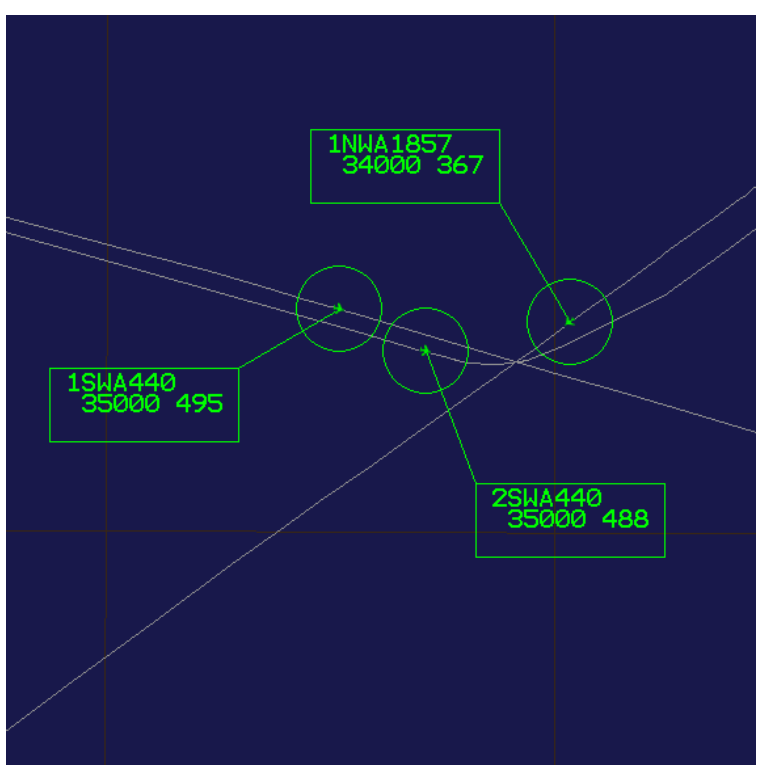

Figure 6. Example of pilot model/ conflict prevention system failure

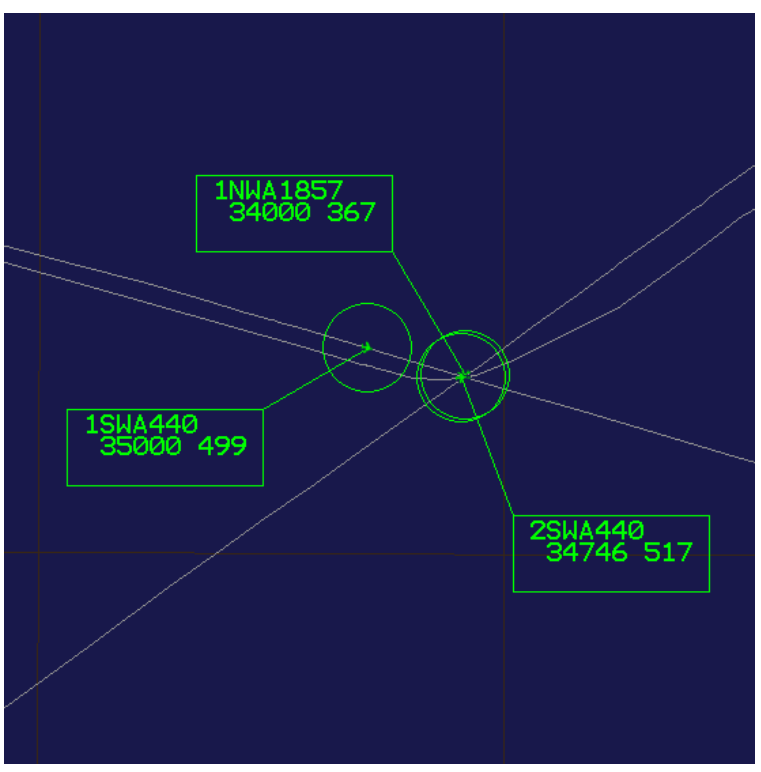

Figure 7. Example of poor recovery maneuver

2SWA440 is initially at $35 \mathrm{kft}$ and 1 NWA1857 is at $34 \mathrm{kft}$, see figure 6.

2SWA440 detects a conflict with a third aircraft, 1SWA440, which is overtaking 2SWA440 along the same flight track. This causes $2 S W A 440$ to initiate a conflict resolution descent. An almost immediate LoS with 1NWA1857 occurs

In this case, the conflict prevention system had altitude bands blocking a descent but the pilot model still commanded 2SWA440 to descend. The heading change occurs after the LoS has occurred, and is a recovery maneuver built into the pilot model since KB3D does not provide resolutions once aircraft are in LoS. The recovery maneuver is also a poor choice since this brings it back across the track of 1SWA440, see figure 7. 


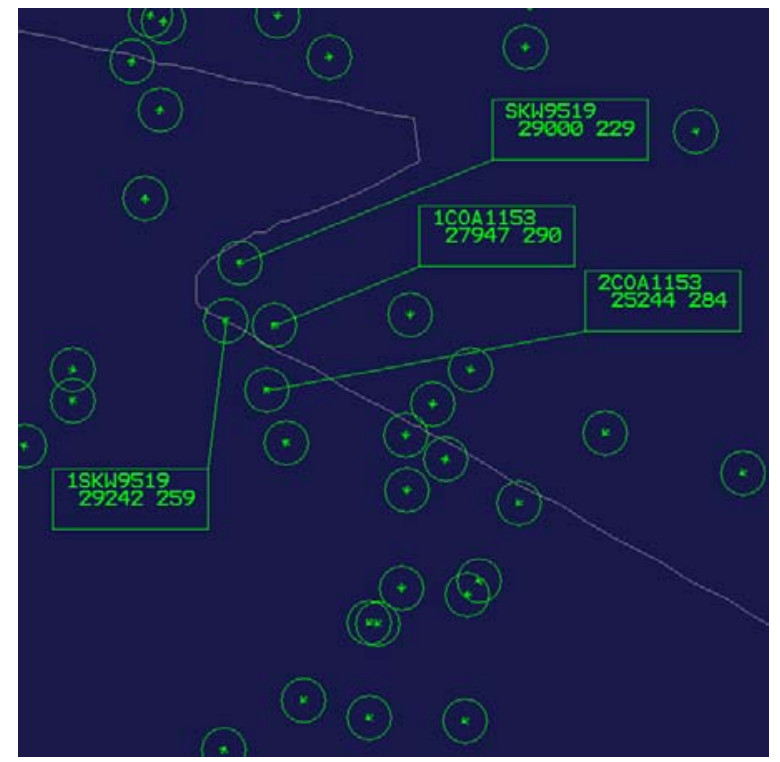

Figure 8. Example of four aircraft encounter

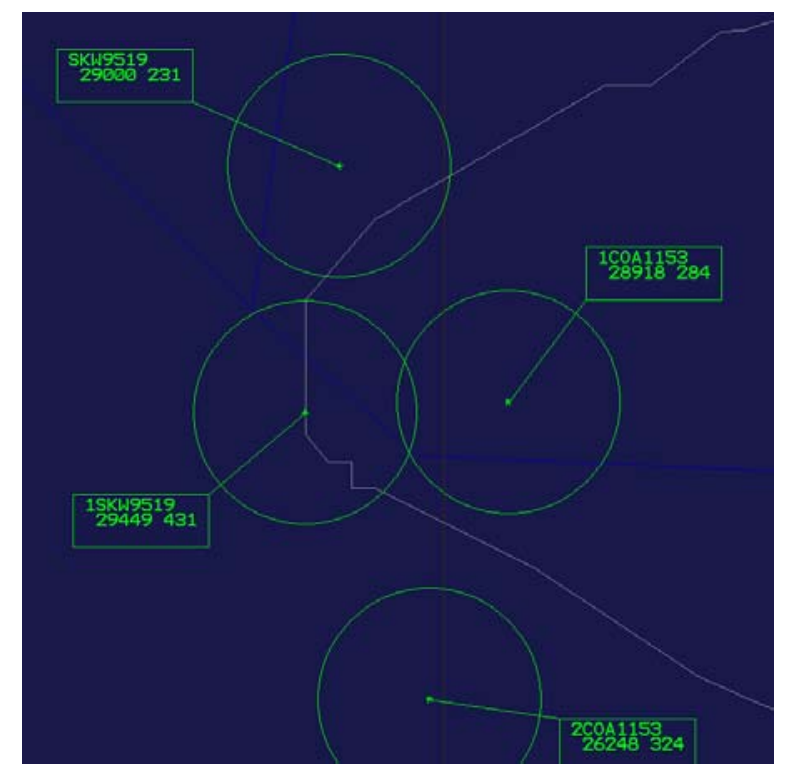

Figure 9. Example of poor resolution choice

This is a complex encounter with four aircraft involved, see figure 8. 1COA1153 is at 28 $\mathrm{kft}$ and climbing, 1SKW9519 is at $29 \mathrm{kft}$ and climbing. 1SKW9519 detects a conflict with a third aircraft 2COA1153 and performs a heading resolution. This puts 1SKW9519 into conflict with a fourth aircraft SKW9519. 1SKW9519 performs another heading resolution that takes it behind SKW9519 and avoids a loss of separation with SKW9519, but this causes an immediate conflict with 1COA1153 that leads to a LoS; see figure 9. Given a choice of maneuver from the CD\&R algorithm, a human pilot may have been able to choose a better resolution. The ASAS concept has the pilot make the final determination of the resolution maneuver chosen from one of the resolution options provided by the automation. 


\section{X AFR plus 1X IFR Mixed Equipage Scenario}

\section{N81432 AFR and AAL1163 IFR}

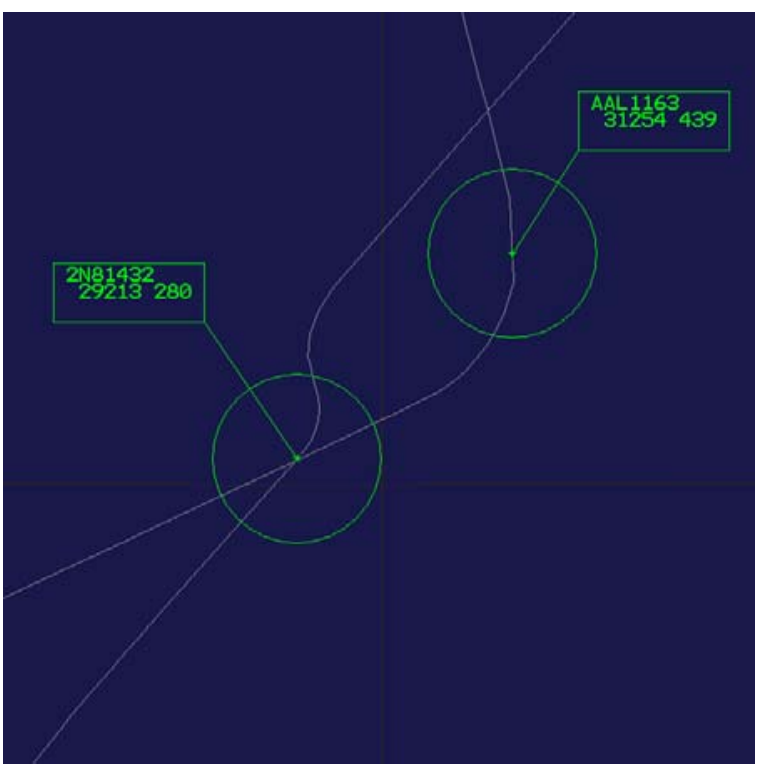

Figure 10. Example of AFR/ IFR aircraft encounter

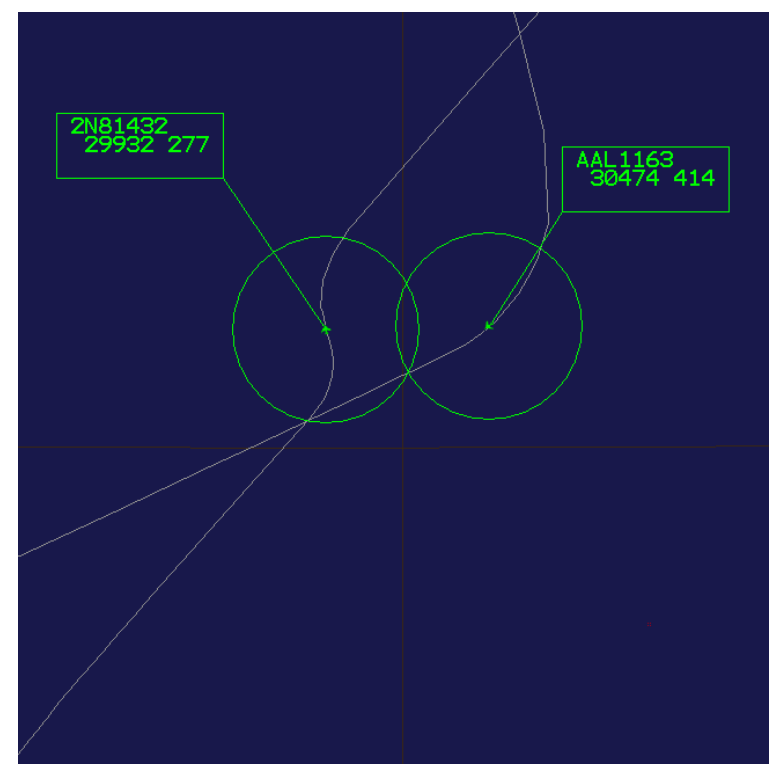

Figure 11. Example of IFR maneuver into short-term conflict

$2 N 81432$ is initially at $29 \mathrm{kft}$ and climbing, $A A L 1163$ is at $31 \mathrm{kft}$ and descending; see figure 10. AAL1163, the IFR aircraft, makes a heading change that causes a short-term conflict with 2N81432, with time to LoS of 31 seconds; see figure 11 . IFR aircraft are not equipped with a conflict prevention system and the simulation does not have a controller model, so IFR aircraft do not attempt to avoid conflicts. 2N81432 attempts a heading resolution, but does not have time to complete the maneuver.

\section{Efficiency}

NAS-wide simulation with full traffic densities over all regions of airspace is the best means to obtain reliable efficiency metrics. This is not possible using TMX, because TMX currently has a limit of 2000 airborne flights. At three times current demand levels, around 15,000 to 20,000 flights may be airborne in the NAS at the peak time.

Interpretation of results relating to efficiency is subject to the following caveats:

1. The AFR results overstate the efficiency of flight because full traffic density is not achieved outside of the experiment volume.

2. The IFR results are from simulation of actual recorded trajectories that include all conflict resolution maneuvers. These trajectories are from the real NAS, so all IFR aircraft experienced the full traffic density throughout the flight. AFR flights experienced full traffic density in the experiment area only. It is therefore not valid to compare IFR and AFR flight efficiencies. 
3. IFR flights may purposely deviate from great-circle routes to follow a more wind optimal route or to avoid restricted airspace, weather or turbulence. Therefore, attributing the entire IFR distance penalty to restricted air-routes and controller resolution advisories is not valid.

4. The scope of this study was en route, so Tactical ASAS is active from departure fix until the aircraft leaves the experiment volume. Consequently, the efficiency metrics do not include the arrival or departure flight segments.

However, given the caveats, the simulation results show some interesting trends, as analyzed in the following sections.

\section{Distance, Time and Fuel}

Table 7 presents the mean increase in average flight distance, time of flight and fuel used for the IFR and AFR-only scenarios. (The efficiency of the mixed equipage scenarios was not analyzed).

The basis for comparison is the same aircraft flying an unimpeded great-circle route, using a fuel-efficient trajectory computed by TMX. The IFR and AFR flights are not compared directly for reasons explained above. The data are for the flight trajectory from departure fix to the arrival fix.

\begin{tabular}{|l|r|r|l|}
\hline & Distance (nm) & Time (seconds) & Fuel (lbs) \\
\hline IFR & $17.0(2.5 \%)$ & $-110.7(-1.9 \%)$ & $500.0(5.8 \%)$ \\
\hline 1X AFR & $2.5(0.4 \%)$ & $11.5(0.2 \%)$ & $200.0(2.4 \%)$ \\
\hline 2X AFR & $6.9(1.0 \%)$ & $45.3(0.7 \%)$ & $300.0(4.0 \%)$ \\
\hline 3X AFR & $12.1(1.8 \%)$ & $86.7(1.4 \%)$ & $500.0(5.4 \%)$ \\
\hline
\end{tabular}

Table 7. Mean increase in flight distance, time and fuel used.

(Compared to unimpeded great-circle routes.)

The IFR flight distance was somewhat more than the great-circle distance, with a significant excess fuel burn. However, the IFR flights actually had a mean flight time that was less than the unimpeded great-circle flights. Therefore, IFR flights are flying somewhat faster than the TMX computed fuel-efficient speed. In addition, the excess fuel burn might be partially due to IFR aircraft flying at altitudes that are not fuel-optimal because of TFM constraints.

The 1X AFR mean excess flight distance and excess fuel burn was small compared to the unimpeded flights. For AFR flights, this excess is the penalty that arises from conflict resolution maneuvers. The penalty increases as the demand level increases as expected.

\section{RTA Capability}

Table 8 shows the ability of aircraft to meet an RTA at the arrival fix. Aircraft used the closed-loop algorithm modeled in TMX to adjust aircraft speed within their flight envelope, to meet the RTA. This allows the aircraft to compensate for trajectory deviations caused by e.g. conflict resolution maneuvers. 


\begin{tabular}{|l|r|r|}
\hline & $\begin{array}{c}\text { \% Flights +- } \\
\text { 5 Sec. of RTA }\end{array}$ & $\begin{array}{c}\text { \% Flights +- } \\
\text { 10 Sec. of RTA }\end{array}$ \\
\hline 1X AFR & 94.7 & 95.2 \\
\hline 2X AFR & 83.8 & 85.3 \\
\hline 3X AFR & 74.2 & 76.1 \\
\hline
\end{tabular}

Table 8. Percentage of flights meeting RTA.

Almost 95\% of aircraft meet the RTA within 5 seconds for the $1 \mathrm{X}$ scenario. However, the RTA meeting capability degrades as demand increases.

Figure 12 shows the probability distribution of the difference between RTA and actual time of arrival.

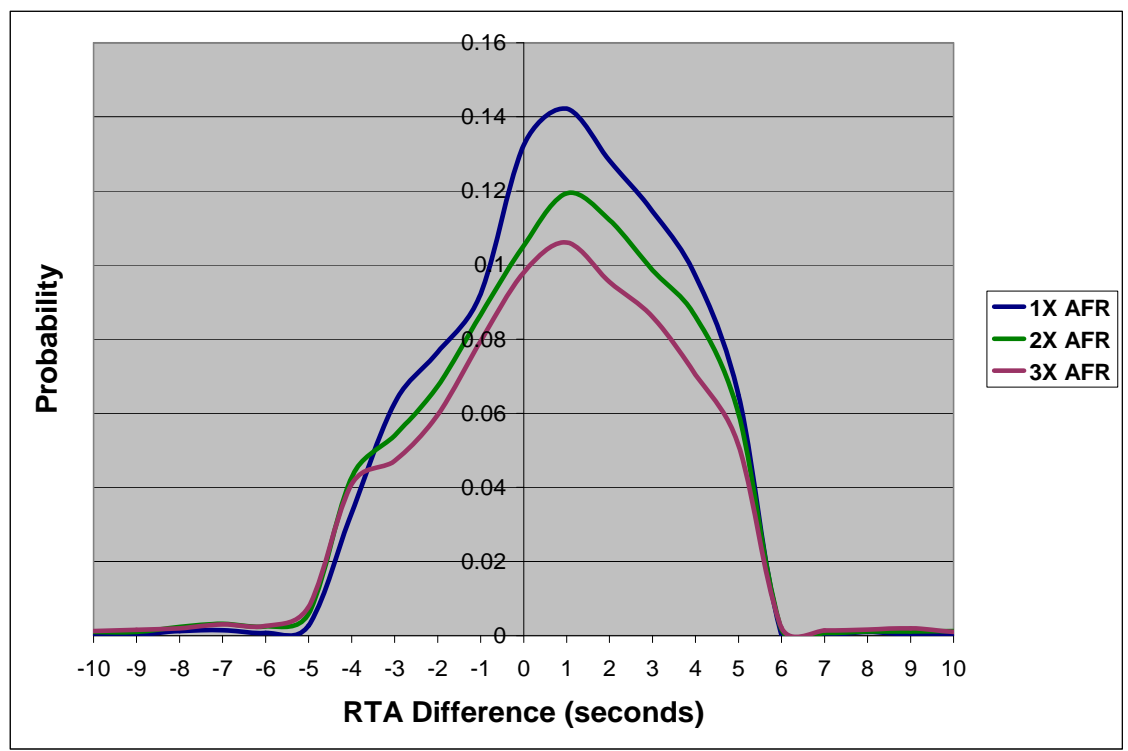

Figure 12. Difference in actual and required time at arrival fix.

Although most flights manage to meet the RTA within 6 seconds there are a number of outliers, particularly for the $3 \mathrm{X}$ demand. One cause is the increased number of conflicts as traffic densities increase. However, it may be possible to improve the RTA algorithm. 


\section{Discussion of Results}

\section{Support of Research Objectives}

The results obtained from analysis of simulation data support the four main research objectives of this study.

Results showed that Tactical ASAS alone accommodated current demand levels with zero LoS while efficiently resolving conflicts and meeting the RTA at the arrival fix. At the $1 \mathrm{X}$ demand level, almost $95 \%$ of AFR aircraft are able to meet the RTA within 5 seconds. (Supports Research Objective 1)

With all aircraft equipped with Tactical ASAS, at the $2 \mathrm{X}$ demand level three LoS occurred, of which two were attributed to an experiment setup issue. At the 3X demand level, the number of LoS increased significantly, but Tactical ASAS alone still efficiently resolved more than $99 \%$ of conflicts. (Supports Research Objective 2)

With the mixed equipage scenarios, at the $2 \mathrm{X}$ demand level, there were $26 \mathrm{LoS}$ compared to only three LoS with all AFR aircraft. However, 10 of the $26 \operatorname{LoS}$ are due to an experiment setup issue and a further six LoS were attributed to the IFR aircraft maneuvering into short-term conflict with an AFR aircraft.

Use of a conflict probe by an air traffic controller may avoid vectoring IFR aircraft into short-term conflicts with AFR. This may enable the performance of Tactical ASAS in a mixed equipage environment to improve considerably, but likely not to the same level as with all AFR aircraft. (Supports Research Objective 3)

Analysis of simulation data uncovered a number of issues with the TMX simulation and KB3D algorithm. (Supports Research Objective 4)

The main issues that require further investigation and investment in simulator and algorithm enhancements are:

\section{TMX Specific Issues}

1. The pilot model within TMX is not sophisticated and can make a poor choice of resolution maneuver.

2. The conflict prevention system may not always predict conflict bands accurately, possibly due to the assumption of linear trajectory propagation.

3. IFR aircraft can maneuver into short-term conflict with AFR due to lack of a controller model.

4. The experiment setup disabled Tactical ASAS by design once an aircraft descended below $17,000 \mathrm{ft}$, but neglected to enable again if the aircraft subsequently climbed above $17,000 \mathrm{ft}$. 
5. TMX data logging is inadequate to allow analysis of all LoS.

6. TMX cannot record and replay a scenario, so post-run visualization of LoS is not possible within TMX.

7. TMX is not currently capable of simulating more than 2000 simultaneously airborne flights. This limits the scope of simulation to a single ATC center at $3 \mathrm{X}$ demand levels. Obtaining NAS wide metrics directly is therefore not possible.

\section{KB3D Specific Issues}

1. KB3D does not continue to provide conflict resolution maneuvers once an aircraft is in LoS, so LoS can be prolonged and lead to smaller CPA.

2. KB3D does not always predict conflicts with sufficient time to avoid LoS, possibly due to the assumption of linear trajectory propagation.

3. KB3D does not take into account aircraft performances, so it can provide resolution maneuvers that exceed aircraft performance. 


\section{Future Research}

The most common cause of LoS was an AFR or IFR aircraft maneuvering into a short-term conflict with another AFR aircraft that did not leave sufficient time for resolution.

For IFR aircraft, a conflict-probe that indicates to the controller when a maneuver would cause a short-term conflict with an AFR aircraft could be one solution. This would require implementation as an algorithm and controller model within TMX.

For AFR aircraft, the conflict prevention system should provide sufficient information to the pilot to avoid maneuvering into short-term conflicts. The current TMX model implementations did not always achieve this.

The TMX pilot model contains some limitations and is the subject of research to improve the sophistication of the decision-making. Any modifications to the pilot model that result in improved performance might indicate the kind of information that can be displayed to a human pilot to aid decision making.

Enhancements currently under consideration for future implementation are:

1. Have the conflict prevention system provide the time to predicted loss of separation for any maneuvers that create short-term conflicts. Such an indication could allow the TMX pilot model to make an informed choice of maneuver when all resolutions lead to short-term conflicts.

2. Calculate a measure of the traffic complexity in the region of the provided resolution maneuvers. This could help the pilot model to avoid maneuvering the aircraft into a complex situation if a choice of maneuver is available.

3. Check all resolutions provided by KB3D for physical feasibility and indicate the margin or lack of, between the aircraft maximum aircraft performance. This could allow the pilot model to make a better choice of maneuver, when a choice is available. If there is not a feasible maneuver, then other options might be possible; e.g. temporarily reduce the protected zone for conflict prediction. Reducing the protected zone for short-term conflicts does not necessarily lead to LoS, since both aircraft will maneuver in a coordinated way. The resolution maneuvers provided by KB3D avoid LoS even if only one aircraft maneuvers, so a reduced protected zone may still prevent LoS. The maneuver required will be less if the protected zone is smaller.

4. Improve the accuracy of trajectory prediction and calculate the uncertainty bounds dynamically rather than use a fixed buffer. This is particularly important in the vertical dimension, since the altitude separation standard is very much smaller than the lateral separation standard. It may be possible to e.g. assume a constant Mach climb, rather than propagate linearly. It may be possible to use e.g. a larger vertical uncertainty buffer when it is determined that an aircraft is not in level flight. This would benefit both CD\&R and conflict prevention. 
Once the Tactical ASAS system has been improved by incorporation of enhancements, then other elements of a complete integrated ASAS can be incorporated into the simulation. These elements include:

1. Strategic, intent-based conflict detection and avoidance with a longer look-ahead time than that of the tactical system studied here.

2. Precision merging and spacing to enable transition into the terminal area, beyond the en-route system studied here.

3. Automated traffic flow management that will predict regions of excessive traffic density and complexity and compute solutions to avoid such regions. 


\section{Conclusions}

The conclusions stated here, are valid for the experiment conditions defined, using the KB3D tactical CD\&R algorithm combined with the TMX P-ASAS conflict prevention system. This study did not include system errors and did not include full traffic density outside of the Fort Worth center airspace. Some problems with the experiment set up led to some LoS not attributable to ASAS. Enhancements to the simulation set up, KB3D and PASAS should further improve performance.

The conclusions from this study are:

- The KB3D CD\&R algorithm, using aircraft state data only, combined with the PASAS conflict prevention system, effectively prevented nearly all losses of separation up to twice-current demand levels for the AFR-only scenario. For the 1X AFR scenario, all conflicts were resolved without any losses of separation. For the 2X AFR scenario, 99.9\% of conflicts were resolved with three losses of separation, only one of which was attributed to Tactical ASAS.

- At three times the current demand level and for mixed AFR and IFR scenarios, the number of losses of separation increases. Even so, 99.5\% of conflicts are resolved for the 3X AFR case, 98.9\% for the 1X IFR + 1X AFR case and 99.1\% for the $1 \mathrm{X}$ IFR + 2X AFR case.

- For mixed AFR and IFR scenarios, some losses of separation resulted from IFR aircraft maneuvers that caused short-term conflicts with AFR. One solution could be to alert the controller to conflict-producing maneuvers by trial planning before requesting an IFR aircraft to maneuver. In addition, providing AFR aircraft with knowledge of the short-term intent of IFR aircraft may reduce the occurrence of controller IFR-to-AFR conflict alerts.

- The conflict resolution maneuvers provided by the KB3D CD\&R algorithm are efficient; for the $1 \mathrm{X}$ AFR scenario, the maneuvers result in less than $0.5 \%$ mean increase in flight distance compared with the unimpeded great-circle route. At three times the current demand level the mean increase in distance is still only $1.8 \%$ compared to the great-circle route.

- AFR aircraft can meet their RTA at the arrival fix; almost $95 \%$ are within 5 seconds of the RTA, for the $1 \mathrm{X}$ AFR scenario. This degrades to $74 \%$ within 5 seconds for the $3 X$ AFR scenario.

The reasons for many of the observed LoS are understood; others are still under investigation. An on-going research effort includes implementing improvements to the KB3D algorithm and changes to the TMX simulation code to improve performance of the Tactical ASAS component.

With these improvements, the number of losses of separation is expected to reduce. As one component of a complete ASAS, tactical CD\&R is part of a layered approach to separation assurance, and is not expected to prevent all losses of separation when used alone. 


\section{References}

1. Joint Planning and Development Office, Concept of Operations for the Next Generation Air Transportation System, Version 2.0, 13 June 2007

2. Bilimoria, K., A geometric optimization approach to aircraft conflict resolution. Guidance, Navigation, and Control Conference, volume AIAA 2000-4265, Denver, CO, August 2000.

3. Hoekstra, J, Designing for Safety: the Free Flight Air Traffic Management Concept, November 2001, ISBN-90-806343-3-6

4. Swenson, H., Barhydt, R., Landis, M., Next Generation Air Transportation System (NGATS) Air Traffic Management (ATM)-Airspace Project, June 2006, NASA LaRC, Hampton, VA

5. Bussink, F.J.L., Hoekstra, J., Heesbeen, W., Traffic Manager: A Flexible Desktop Simulation Tool Enabling Future ATM Research, $24^{\text {th }}$ Digital Avionics Systems Conference, October 2005, Washington DC

6. Nuic, A., 2003, User Manual for the Base of Aircraft Data (BADA), Revision 3.5, Eurocontrol Experimental Centre, Bretigny, France

7. Munoz, C., Siminiceanu, R., Carreno, V., Dowek, G., KB3D Reference Manual Version 1.a, NASA/TM-2005-213769, NASA LaRC, Hampton, VA, http://research.nianet.org/fm-at-nia/KB3D

8. Owre, S., Rushby, J., Shankar, N., “PVS: A Prototype Verification System”, International Conference on Automated Deduction, Saratoga, New York, 1992.

9. AwSim User Manual Version 3.5, March 22, 200, A-REF-041, Aerospace Engineering and Research Associates 


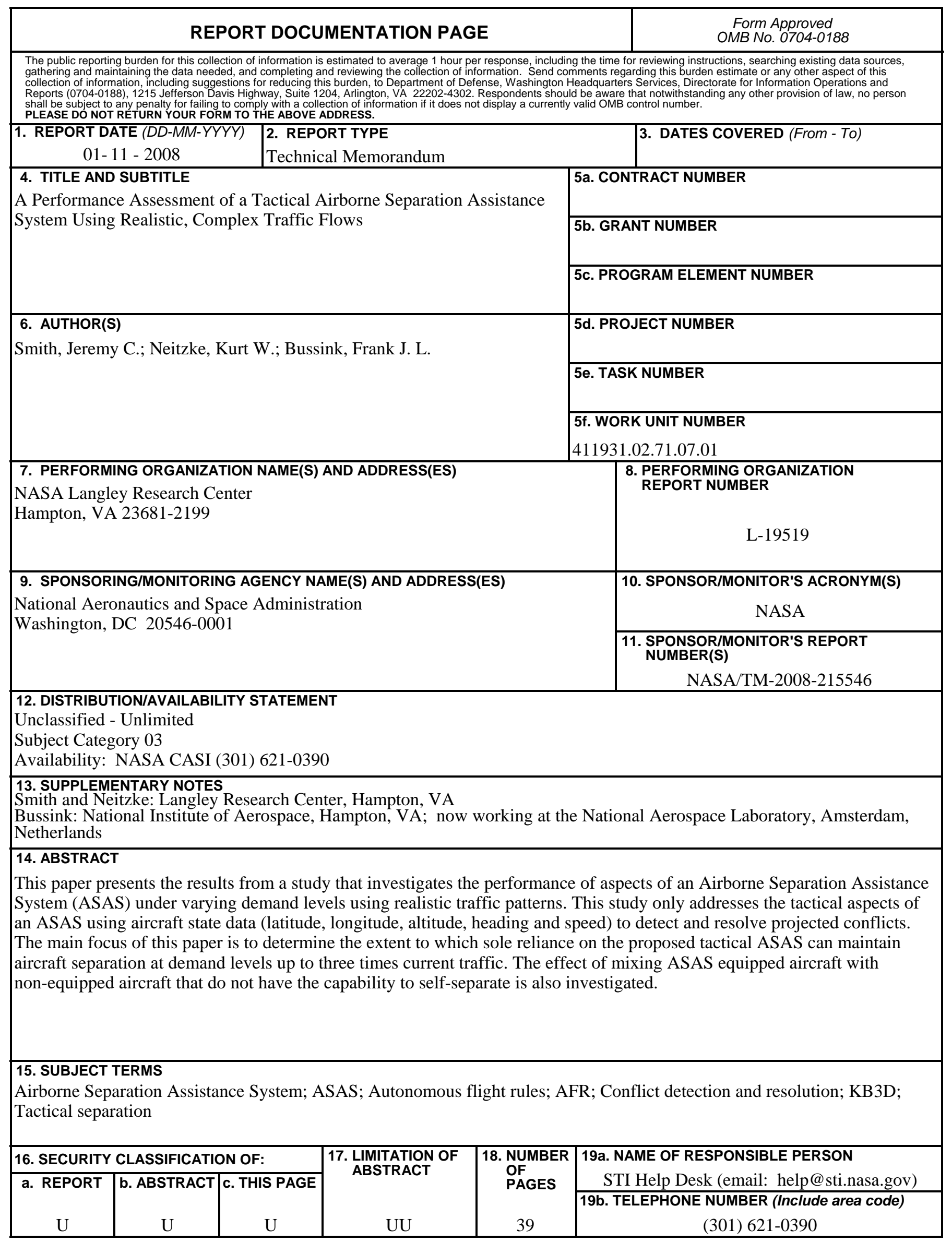

